ARTICLE

\title{
Vacancies on 2D transition metal dichalcogenides elicit ferroptotic cell death
}

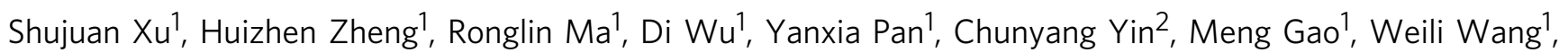
Wei Li ${ }^{1}$, Sijin Liu ${ }^{2}$, Zhifang Chai ${ }^{1} \&$ Ruibin Li (i) ${ }^{1 凶}$

Sustainable developments of nanotechnology necessitate the exploration of structure-activity relationships (SARs) at nano-bio interfaces. While ferroptosis may contribute in the developments of some severe diseases (e.g., Parkinson's disease, stroke and tumors), the cellular pathways and nano-SARs are rarely explored in diseases elicited by nano-sized ferroptosis inducers. Here we find that $\mathrm{WS}_{2}$ and $\mathrm{MoS}_{2}$ nanosheets induce an iron-dependent cell death, ferroptosis in epithelial (BEAS-2B) and macrophage (THP-1) cells, evidenced by the suppression of glutathione peroxidase 4 (GPX4), oxygen radical generation and lipid peroxidation. Notably, nano-SAR analysis of 20 transition metal dichalcogenides (TMDs) disclosures the decisive role of surface vacancy in ferroptosis. We therefore develop methanol and sulfide passivation as safe design approaches for TMD nanosheets. These findings are validated in animal lungs by oropharyngeal aspiration of TMD nanosheets. Overall, our study highlights the key cellular events as well as nano-SARs in TMD-induced ferroptosis, which may facilitate the safe design of nanoproducts.

\footnotetext{
${ }^{1}$ State Key Laboratory of Radiation Medicine and Protection, School for Radiological and Interdisciplinary Sciences (RAD-X), Collaborative Innovation Center of Radiological Medicine of Jiangsu Higher Education Institutions, Soochow University, Suzhou 215123 Jiangsu, China. ${ }^{2}$ State Key Laboratory of Environmental Chemistry and Ecotoxicology, Research Center for Eco-Environmental Sciences, Chinese Academy of Sciences, 18 Shuangqing Road, Beijing 100085, China. ${ }^{凶}$ email: liruibin@suda.edu.cn
} 
s physicochemical properties of engineered nanomaterials (ENMs) were found to significantly impact their toxicities, structure-activity relationships (SARs) of ENMs have been highly underlined in nanobiology research ${ }^{1}$. Some progresses on nano-SARs have been made in ENM-induced apoptosis $^{2}$, carcinogenesis ${ }^{3}$, autophagic ${ }^{4}$, and inflammatory effects ${ }^{5}$. For instance, diameter and rigidity of carbon nanotubes are critical characteristics in mesothelial injury and carcinogenesis 3 ; carbon radicals of graphene oxides are able to induce lipid peroxidation and cell deaths ${ }^{6}$. Recently, two-dimensional (2D) transition metal dichalcogenides (TMDs) as an atomic-layer semiconductor were found to display unique surface activities ${ }^{7}$ and arouse great enthusiasm for their biological effects. The surface area, active edge sites, and aggregation states were found to impact the hazard effects of TMDs in cells and animals ${ }^{8-11}$. For instance, Wang et al. discovered that aggregated $\mathrm{MoS}_{2}$ induced proinflammatory cytokine release in cells and acute lung inflammation in mice, whereas dispersed $\mathrm{MoS}_{2}$ had little effect ${ }^{9}$.

Beside of the above hazard effects, ferroptosis is a newly recognized iron-dependent cell death mechanism, characterized by generation of lipid peroxidation ${ }^{12}$. This unique cell death mechanism closely relates to some serious diseases such as Parkinson's disease ${ }^{12,13}$, stroke $e^{14,15}$ and tumors ${ }^{16}$. Currently, silica nanoparticles are the only non-iron materials that are able to induce ferroptosis in starved M21 cancer cells and cancer-bearing mice ${ }^{17}$. However, the nano-SARs involved in ferroptosis are unexplored, and other nano inducers are rarely reported.

Herein, $\mathrm{WS}_{2}$ and $\mathrm{MoS}_{2}$ nanosheets are found to induce ferroptosis in epithelial (BEAS-2B) and macrophage (THP-1) cells, which are the first port of entry for exposed fine particulates in vivo. To explore the nano-SARs involved in ferroptosis, five 2D TMDs are prepared by exfoliating nanosheets from bulk materials of $\mathrm{WS}_{2}, \mathrm{MoS}_{2}, \mathrm{WSe}_{2}$ and $\mathrm{MoSe}_{2}$ and $\mathrm{BN}$. The toxicity pathways of TMDs are deciphered by examining the molecular initiating events (MIEs) at nano-bio interfaces. We are therefore able to identify the key physicochemical properties that are responsible for ferroptotic cell deaths. The identified nano-SARs are utilized for biocompatible functionalization of $\mathrm{WS}_{2}$ and $\mathrm{MoS}_{2}$ nanosheets. Considering the potential inhalation exposure risks of nanoproducts such as lubricants, semiconductors, and surface coatings, the in vitro results are further validated in animal lungs by oropharyngeal aspiration of TMD materials.

\section{Results}

Assessments of cytotoxicity by 2D TMDs. To prepare 2D materials, bulk $\mathrm{WS}_{2}, \mathrm{MoS}_{2}, \mathrm{WSe}_{2}, \mathrm{MoSe}_{2}$, and $\mathrm{BN}$ materials were ground and dispersed in aqueous Pluronic F68 solutions for sufficient ultrasonication to exfoliate nanosheets. The suspensions were ultra-centrifuged to collect the supernatants containing monolayer or few-layer nanosheets for sufficient dialysis. The purified 2D materials were characterized by atomic force microscope (AFM), Raman spectrometer, Zeta potential and hydrodynamic analyzer for structure interpretations. AFM images showed that all five 2D materials had irregular planner structures with diameters and heights at $16-264 \mathrm{~nm}$ and $0.3-1.8 \mathrm{~nm}$, respectively (Fig. 1a, Supplementary Fig. 1A). The 2D planner structures were further evidenced by the Raman characteristic peaks, e.g., $\mathrm{E}_{2 \mathrm{~g}}$ or $\mathrm{A}_{1 \mathrm{~g}}$ peaks of $\mathrm{WS}_{2}(\sim 347$, $\left.416 \mathrm{~cm}^{-1}\right)^{18}, \mathrm{E}_{2 \mathrm{~g}}^{1}$ or $\mathrm{A}_{1 \mathrm{~g}}$ peaks of $\mathrm{MoS}_{2}\left(\sim 380,407 \mathrm{~cm}^{-1}\right)^{19}$ and $\mathrm{WSe}_{2}\left(\sim 252,257 \mathrm{~cm}^{-1}\right)^{20}, \mathrm{~A}_{1 \mathrm{~g}}$ peak of $\mathrm{MoSe}_{2}\left(\sim 242 \mathrm{~cm}^{-1}\right)^{21}$ and $\mathrm{E}_{2 \mathrm{~g}}^{1}$ peak of $\mathrm{BN}\left(\sim 1367 \mathrm{~cm}^{-1}\right)^{22}$. The surface charges and hydrodynamic sizes were assessed in water and cell culture media (Supplementary Table 1). All five materials showed negative surface charges with zeta potentials in the range of -5.8 to $-25.9 \mathrm{mV}$ in water, and they had similar hydrodynamic sizes in DI water (90-128 nm), RPMI 1640 (96-134 nm) and bronchial epithelial growth medium (BEGM, 92-135 nm). As shown in Supplementary Fig. 1B, except for $\mathrm{WSe}_{2}$, other four materials exhibited good suspension stability in RPMI 1640 for a period of $48 \mathrm{~h}$ incubation.

Then BEAS-2B and THP-1 cells were exposed to the 2D materials for assessments of their bio-effects. First, we assessed the impacts of $2 \mathrm{D}$ materials on cell proliferation by measuring the endogenous ATP levels. As shown in Fig. 1b, c and Supplementary Fig. 2, ATP assay suggested that $\mathrm{WS}_{2}$ and $\mathrm{MoS}_{2}$ induced dose- and time-dependent cell death in BEAS-2B and THP-1 cells, whereas $\mathrm{BN}, \mathrm{MoSe}_{2}$, and $\mathrm{WSe}_{2}$ had little effect on cell viability. After $48 \mathrm{~h}$ exposure at the highest dose of $200 \mu \mathrm{g} / \mathrm{mL}$, $\mathrm{WS}_{2}$ and $\mathrm{MoS}_{2}$ induced 57.3 and $43.8 \%$ cell deaths, respectively. This cytotoxic effect could be further validated by examining the activities of dehydrogenases in cellular metabolic process via MTS assay. Then we attempted to differentiate the cell death types by dynamically visualizing cell morphology changes under a timelapse microscope. Doxorubicin (DOX) was used as apoptosis inducer $^{23}$ and a formula of TNF- $\alpha$ and cycloheximide (CHX) was used as necrosis inducer ${ }^{24}$. The cell growth movie showed that $\mathrm{WS}_{2}$ treated cells preferred to recruit around particle agglomerates, fuse together and lyse (Movie S1), which is similar to the death stages in necrosis (Movie S2) but different to apoptosis (Movie S3). However, necrostatin-1 (Nec-1) as a conventional inhibitor of necrosis was failed to ameliorate $\mathrm{MoS}_{2} / \mathrm{WS}_{2}$ induced cytotoxicity. Apoptosis inhibitor (Z-VAD-FMK) neither had effects (Fig. 1d). We therefore speculated that a different cytotoxicity mechanism may be involved in $\mathrm{MoS}_{2}$ and $\mathrm{WS}_{2}$ induced cell deaths.

Endocytosis was required in TMD-induced cell deaths. To decipher the detailed mechanism, we first examined whether the metal ions released from $\mathrm{MoS}_{2}$ and $\mathrm{WS}_{2}$ were responsible for their cytotoxicity. Viability test of BEAS-2B cells exposed to the supernatants and pellets of TMD suspensions showed that particle dissolution had little effects to cell proliferation (Supplementary Fig. 3). We then visualized the cellular distribution of $2 \mathrm{D}$ TMD nanosheets by transmission electron microscope (TEM). As shown in Fig. 2a, suspected TMD agglomerates with high electron densities could be visualized in the vesicular structures as well as extracellular regions. Energy Dispersive X-ray (EDX) analysis confirmed the presence of $\mathrm{W}$ and Mo elements in these agglomerates. The cellular distribution was further confirmed by confocal microscopy imaging of fluorescein isothiocyanate (FITC)-labeled $\mathrm{WS}_{2}$ and $\mathrm{MoS}_{2}$ nanosheets in BEAS-2B cells. As shown in Supplementary Fig. 4, the labeled nanosheets had a colocalization with lysosomes lighted by a lysotracker. Next, we questioned whether the cytotoxicity of $\mathrm{WS}_{2}$ and $\mathrm{MoS}_{2}$ resulted from cellular internalized or extracellular nanosheets. Cytochalasin D, an inhibitor of cell actin monomer polymerization, was used for the blockage of nanoparticle endocytosis. As shown in Fig. 2b, cytochalasin $\mathrm{D}$ pretreatment significantly reduced the toxic effects of $\mathrm{WS}_{2}$ and $\mathrm{MoS}_{2}$ in BEAS-2B cells. These data suggested that endocytosis was required in cell deaths induced by $\mathrm{WS}_{2}$ and $\mathrm{MoS}_{2}$.

Based on these observations, we speculated that lysosomal compartment is likely to be the primary scene of initial toxicity events. To decipher the MIEs in lysosomes, we comprehensively examined the physicochemical property changes (surface area, oxidation potential, surface charge and dissolution) of TMD nanosheets in phagolysosomal simulated fluids (PSF) as well as their interactions with lysosome compartments. We identified strong oxidation capability and phospholipid-binding affinity on $\mathrm{MoS}_{2}$ and $\mathrm{WS}_{2}$ surfaces, respectively. As shown in Fig. 2c, unpaired electrons of Mo 
a
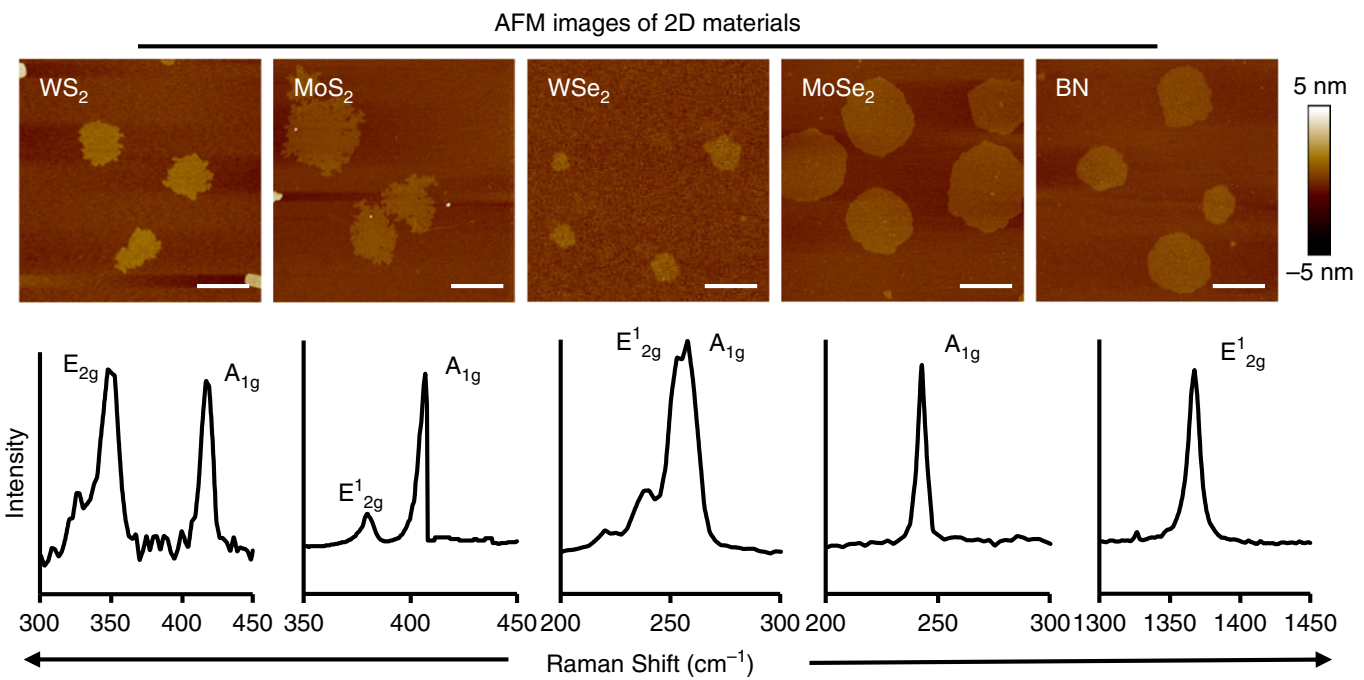

b
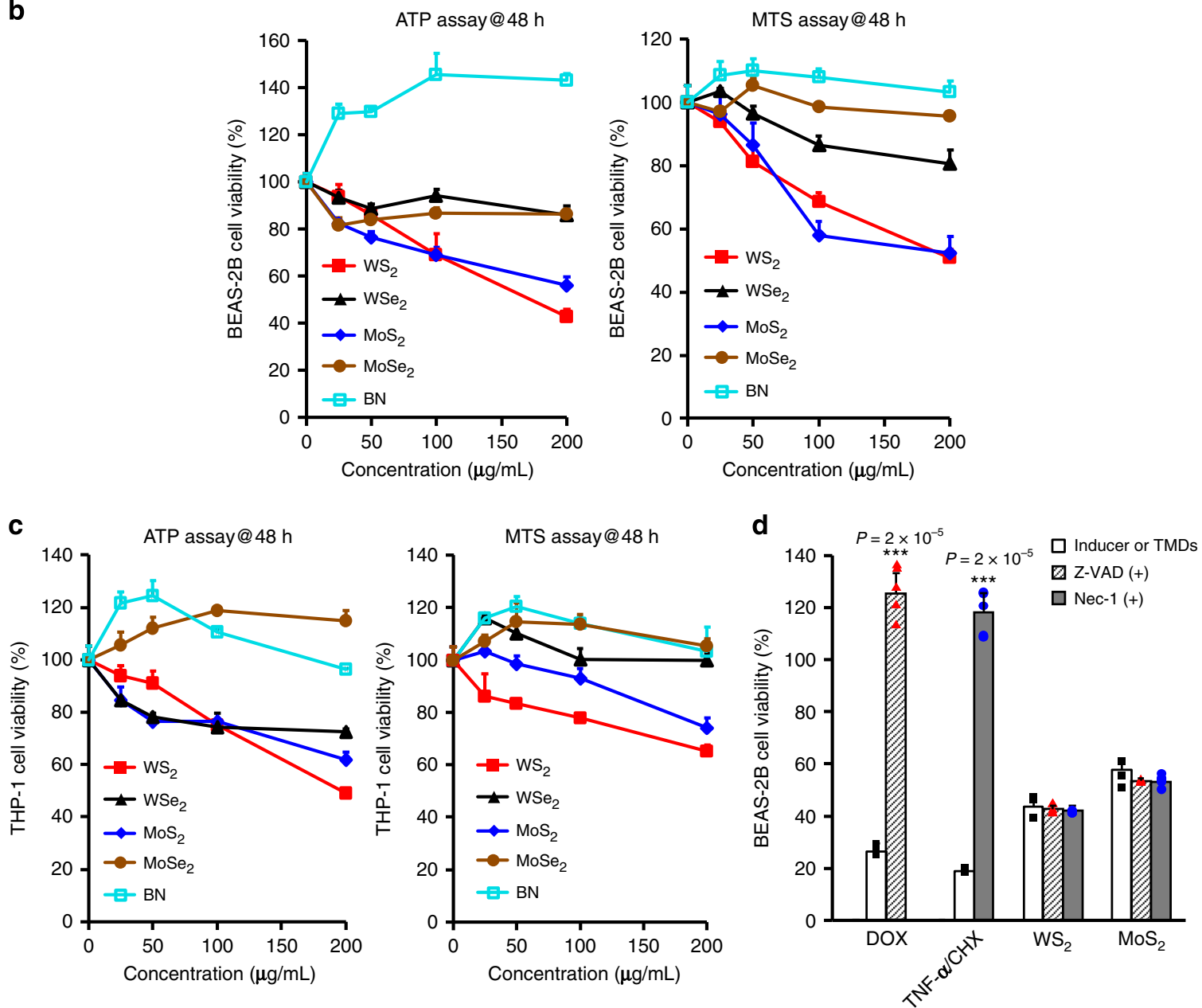

Fig. 1 Characterization of 2D TMDs and their cytotoxicity assessments. a Representative AFM images and Raman spectra of 2D TMDs. A drop of 2D TMDs suspension $(50 \mu \mathrm{g} / \mathrm{mL}$ ) was placed on a mica plate, and then dried in vacuum drying oven for AFM observation (scale bar, $100 \mathrm{~nm}$ ). 2D TMDs stock solutions $(5 \mathrm{mg} / \mathrm{mL})$ were freeze-dried to form powder for Raman spectra detection. Shown are the representative images from three independent experiments. Cell viability test in $\mathbf{b}$ BEAS-2B and c THP-1 cells. BEAS-2B and THP-1 cells were exposed to $2 \mathrm{D}$ TMDs at $0-200 \mu \mathrm{g} / \mathrm{mL}$ for $48 \mathrm{~h}$. The cell viability was examined by detecting luminescence and absorbance of substrates in ATP and MTS assays $(n=3$ biologically independent cell samples). Data are presented as mean values $\pm \mathrm{SD}$. $\mathbf{d}$ Effects of apoptosis and necrosis inhibitors on $\mathrm{MoS}_{2}$ and $\mathrm{WS}_{2}$ induced cytotoxicity. BEAS-2B cells pretreated with $50 \mu \mathrm{M} \mathrm{Nec}-1,20 \mu \mathrm{M}$ Z-VAD-FMK for $1 \mathrm{~h}$ were exposed to $2 \mu \mathrm{g} / \mathrm{mL} \mathrm{DOX}$, formula of $100 \mathrm{ng} / \mathrm{mL} \mathrm{TNF-} \alpha$ and $1 \mu \mathrm{g} / \mathrm{mL} \mathrm{CHX,200 \mu g/mL} \mathrm{WS} 2$ and MoS 2 for $48 \mathrm{~h}$ to determine cell viability by ATP assay ( $n=3$ biologically independent cell samples). Data are presented as mean values \pm SD. ${ }^{\star \star \star} p<0.001$ compared to inducer or TMD treatments by two-tailored Student $t$-test. 


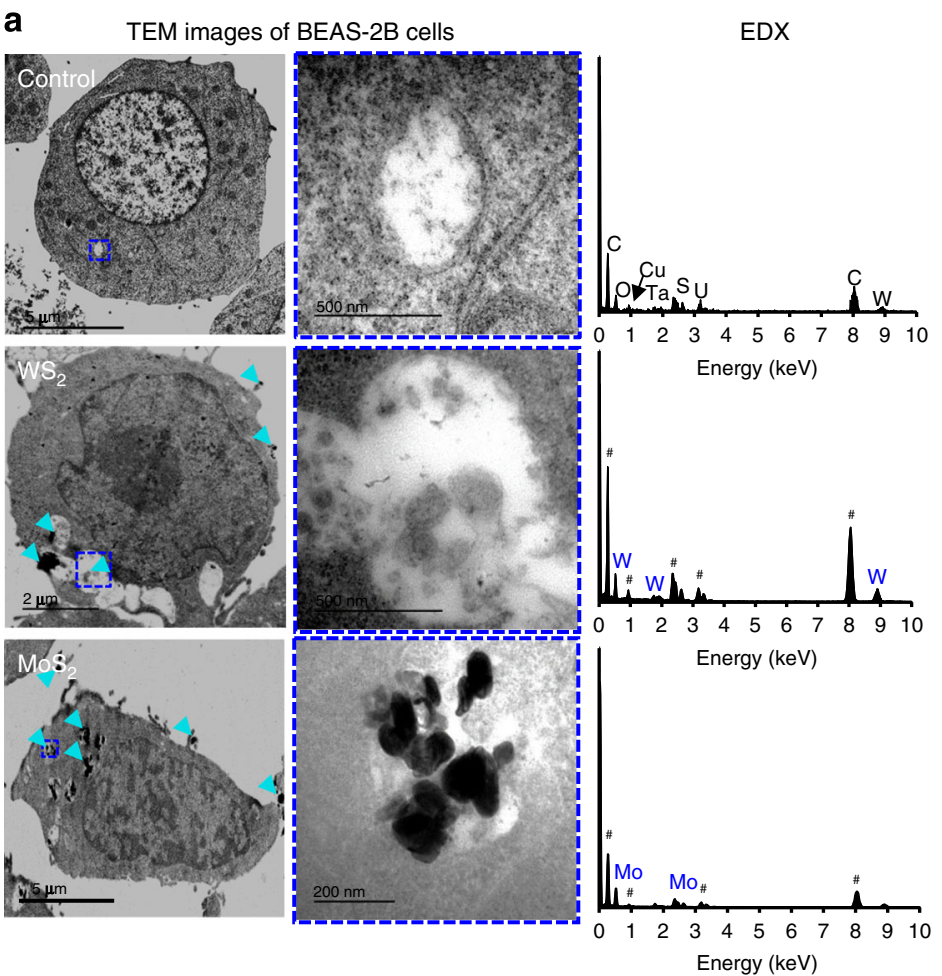

b

C

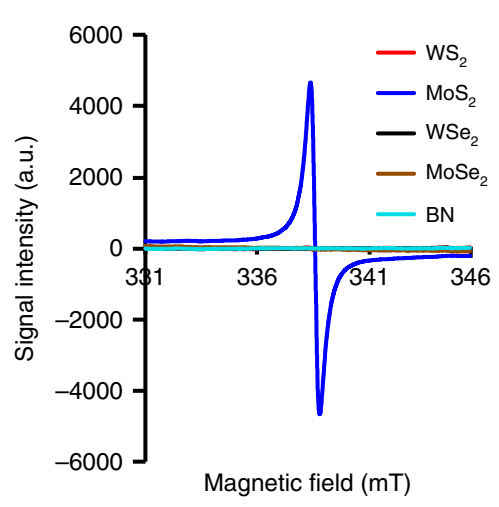

d

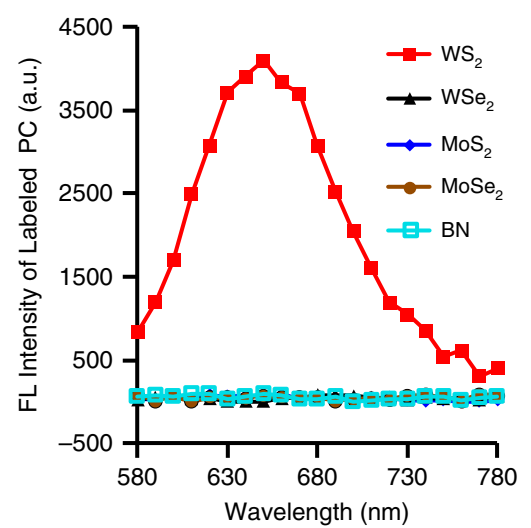

atoms could be detected by the peaks at $338 \mathrm{mT}$ on the spectra of electron paramagnetic resonance (EPR). $\mathrm{MoS}_{2}$ therefore exhibited strong oxidation potentials, evidenced by the increased fluorescence of oxidized dihydrodichlorofluorescein $\left(\mathrm{H}_{2} \mathrm{DCF}\right)$ by $\mathrm{MoS}_{2}$ nanosheets in PSF. In addition, strong adsorption of phospholipids was detected on $\mathrm{WS}_{2}$ surfaces using Nile Red
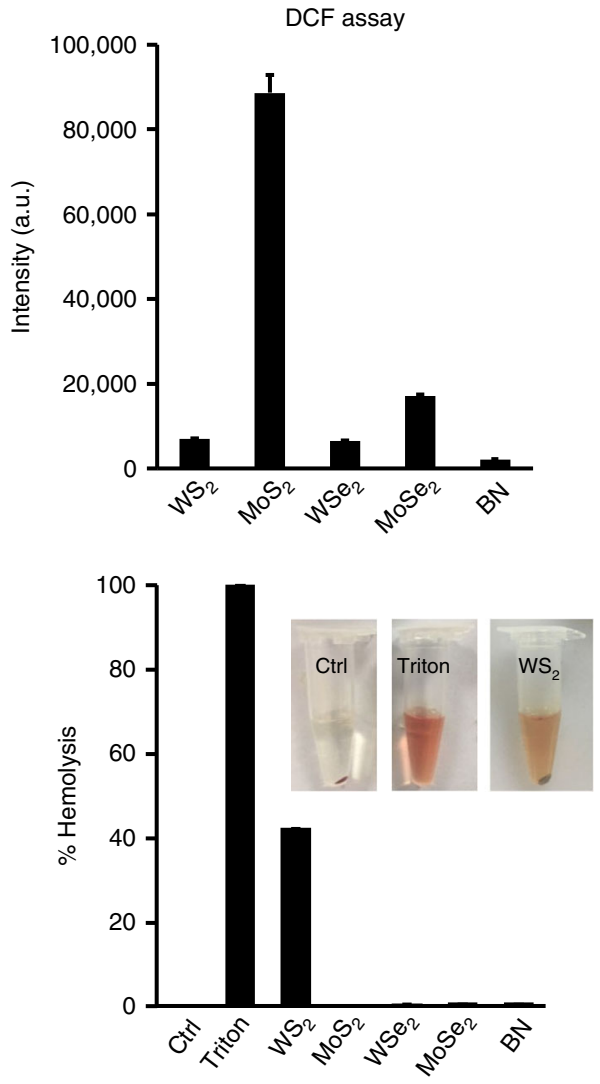

labeled phosphatidylcholine (PC) liposomes, which may be attributed to the high binding affinity of unsaturated $\mathrm{W}$ elements with phosphine to form $\mathrm{W}-\mathrm{O}-\mathrm{P}$ bonds ${ }^{25}$. This interaction was further confirmed by a hemolysis analysis where $\mathrm{WS}_{2}$ could induce $42 \%$ hemoglobin release from damaged red blood cells (Fig. 2d). 
Fig. 2 Exploration of key TMD properties responsible for cytotoxicity. a Representative TEM images of TMD distribution in cells. BEAS-2B cells treated by $100 \mu \mathrm{g} / \mathrm{mL} \mathrm{WS} 2$ and $\mathrm{MoS}_{2}$ for $24 \mathrm{~h}$ were collected to fix, stain and prepare slides for TEM observation. Shown are the representative images from three independent cell samples. The cyan arrows represent the TMDs. Symbol (\#) represents background elements. $\mathbf{b}$ Impacts of endocytosis inhibitor on cytotoxicity of $\mathrm{WS}_{2}$ and $\mathrm{MoS}_{2}$. BEAS-2B cells pretreated with $5 \mu \mathrm{g} / \mathrm{mL} \mathrm{CD}$ for $2 \mathrm{~h}$ were exposed to $200 \mu \mathrm{g} / \mathrm{mL} \mathrm{WS}_{2}$ and $\mathrm{MoS}_{2}$ for cell viability test after $48 \mathrm{~h}$ incubation ( $n=3$ biologically independent cell samples). Data are presented as mean values \pm SD. ${ }^{\star} p<0.05,{ }^{\star \star *} p<0.001$ compared to TMD treatments by two-tailored Student $t$-test. c Assessment of surface radicals on TMD surfaces ( $n=3$ independent samples). All 2D materials were subjected to EPR measurement at a $g$ value of 2.003133 (left). The oxidation potentials were assessed by detection of the fluorescence of $\mathrm{H}_{2} \mathrm{DCF}$ after $2 \mathrm{~h}$ incubation with $250 \mu \mathrm{g} / \mathrm{mL}$ of TMDs (right). Data are presented as mean values \pm SD. $\mathbf{d}$ Interactions between TMDs and lipid layers ( $n=3$ independent experiments). The fluorescence of Nile red labeled lipids were detected in supernatants resulting from DSPC liposomes (1 mg/mL) reacted with $200 \mu \mathrm{g} /$ $\mathrm{mL}$ TMDs for $4 \mathrm{~h}$ (left). Hemolysis assay was performed by incubation of fresh mouse blood cells with $100 \mu \mathrm{g} / \mathrm{mL} 2 \mathrm{D}$ TMDs in PBS to detect the absorbance of released hemoglobin in supernatants (right). Data are presented as mean values \pm SD.

Deciphering ferroptosis pathways of $\mathrm{MoS}_{2}$ and $\mathrm{WS}_{2}$ nanosheets. Considering lysosome is an important depository for large amounts of redox-active iron, ferrous ion release was examined in TMD-treated cells. Non-fluorescent FeRhoNox-1 was used to detect labile $\mathrm{Fe}^{2+}$ in cells as this substrate can specifically react with $\mathrm{Fe}^{2+}$ to emit intense fluorescence at $575 \mathrm{~nm}^{26}$. As shown in Fig. $3 \mathrm{a}$, in contrast to the punctate distribution of red dots in control cells, increased $\mathrm{Fe}^{2+}$ leakage was confirmed in $\mathrm{WS}_{2}$ and $\mathrm{MoS}_{2}$ treated cells, displaying diffused distribution pattern of FeRhoNox-1 similar to $\mathrm{Fe}\left(\mathrm{NH}_{4}\right)_{2}\left(\mathrm{SO}_{4}\right)_{2}$ treatment (positive control). Since lysosomal iron release have been reported as the key upstream signals of ferroptosis, we hypothesized that $\mathrm{WS}_{2}$ and $\mathrm{MoS}_{2}$ nanosheets were able to induce ferroptotic cell death. To demonstrate this, we first examined whether the cytotoxicity of $\mathrm{WS}_{2}$ and $\mathrm{MoS}_{2}$ nanosheets was dependent on lysosomal release of $\mathrm{Fe}^{2+}$ by comparing cell viabilities in normal and iron-chelator treated cells. Two clinically used chelators including deferiprone (DFP) and deferasirox (DFX) were exploited to chelate cytosolic iron. As shown in Fig. 3b, DFP and DFX pretreatments significantly ameliorated the toxic effects of $\mathrm{MoS}_{2}$ and $\mathrm{WS}_{2}$, and rescued more than $27.9 \%$ cells, suggesting an iron-dependent cell death pathway. Since transferrin receptors (TfR) serving as the dominant transporter of iron in cell metabolism is very relevant to ferroptosis ${ }^{27}$, TfR knockdown (TfR-KD) is a reliable method to examine ferroptotic cell death ${ }^{28,29}$. The iron-dependent cytotoxic effect of $\mathrm{MoS}_{2}$ and $\mathrm{WS}_{2}$ was also validated in TfR-KD cells. As shown in Fig. 3c, Both $\mathrm{MoS}_{2}$ and $\mathrm{WS}_{2}$ nanosheets induced less cell deaths in TfR-KD cells than those in wide-type (WT) cells. These results well supported our claim on the ferroptosis effect of $\mathrm{MoS}_{2}$ and $\mathrm{WS}_{2}$.

Since redox-active ferrous ions could catalyze the generation of reactive oxygen species (ROS) via Fenton reaction, we reasoned that TMD-induced lysosomal release of $\mathrm{Fe}^{2+}$ might subsequently result in ROS generation. To demonstrate this, nanoparticle treated BEAS-2B cells were stained by nonfluorescent $2^{\prime}, 7^{\prime}$ Dichlorofluorescin diacetate $\left(\mathrm{H}_{2} \mathrm{DCF}-\mathrm{DA}\right)$, which could be oxidized into dichlorofluorescein (DCF) by ROS and emit strong green fluorescence at $529 \mathrm{~nm}$. Confocal microscopy images showed that intensive DCF fluorescence could be visualized in $\mathrm{WS}_{2}$ and $\mathrm{MoS}_{2}$ treated cells, indicating massive ROS generation, whereas DFP/DFX pretreatments could dramatically reduce this effect (Fig. 3d). N-acetyl-cysteine (NAC) and 6-hydroxy-2,5,7,8tetramethylchroman-2-carboxylic acid (Trolox) as scavengers of ROS could completely eliminate the hazard effects of $\mathrm{MoS}_{2} / \mathrm{WS}_{2}$ in BEAS-2B cells (Supplementary Fig. 5). Consequently, we examined a ROS-induced lethal signal of ferroptosis, lipid peroxidation in BEAS-2B cells. Assessments of lipid peroxidation in live cells could be achieved by detecting the oxidation of BODIPY 581/591 C11 reagent, which displays a shift of fluorescence emission peaks from $\sim 590 \mathrm{~nm}$ (red) to $\sim 510 \mathrm{~nm}$ (green) upon oxidation by lipid hydroperoxides. Cumene hydroperoxide $(\mathrm{CH})$ was included as a positive control. As shown in Fig. 3e, $\mathrm{MoS}_{2}$ and $\mathrm{WS}_{2}$ treatment enabled remarkable lipid peroxidation in BEAS-2B cells signified by a ratiometric increment of green vs. red fluorescence, whereas a majority of cells emit uniform red fluorescence of BODIPY 581/591 C11 in untreated cells. As a result, substantial dead cells could be visualized by LIVE/DEAD staining in $\mathrm{MoS}_{2}$ and $\mathrm{WS}_{2}$ treatments, displaying robust red fluorescence of Ethidium homodimer-1 (EthD-1) that is capable of passing through damaged cell membranes and binding with DNA molecules (Supplementary Fig. 6). The green fluorescence of calcein-AM indicated viable cells with intact cell membranes.

To further confirm the ferroptosis mechanism, we examined the impacts of a ferroptosis inhibitor, ferrostatin-1 (Fer-1) on $\mathrm{WS}_{2}$ and $\mathrm{MoS}_{2}$ induced cell deaths. As shown in Fig. 4a, Fer-1 pretreatment could dramatically improve cell viabilities $(24-47 \%$ increments) in BEAS-2B and THP-1 cells exposed to $\mathrm{WS}_{2}$ and $\mathrm{MoS}_{2}$. A reduction of glutathione peroxidase 4 (GPX4) in response to $\mathrm{WS}_{2}$ and $\mathrm{MoS}_{2}$ nanosheets was confirmed by Western blotting (Fig. 4b). Immunoblotting to examine the abundance of GPX4 in BEAS-2B extracts demonstrated that $\mathrm{WS}_{2}$ and $\mathrm{MoS}_{2}$ treatments suppressed $>30 \%$ expression of GPX4 in cells. These results allowed us to decipher the cascaded signaling pathways of TMD-induced ferroptosis. In brief, TMD nanosheets could be endocytosed into lysosomes for digestion. Lysosomal processing of the unsaturated metal atoms on $\mathrm{WS}_{2}$ and $\mathrm{MoS}_{2}$ surfaces may result in lysosomal membrane changes via phospholipid extraction and oxidation damages, respectively. The damaged lysosomal membranes allowed $\mathrm{Fe}^{2+}$ leakage into cytoplasm to serve as catalysts in Fenton reactions and trigger substantial ROS generation, causing lipid peroxidation, membrane deconstruction and cell death.

Exploration of nano-SARs in ferroptosis. Since the active Mo or W atoms resulting from surface vacancies were found to take part in the MIEs of ferroptosis, we hypothesized that the surface vacancy may be the key physicochemical property responsible for the ferroptosis effect of $\mathrm{MoS}_{2}$ and $\mathrm{WS}_{2}$ nanosheets. To demonstrate this hypothesis, we prepared 20 derivatives of TMD nanoparticles to examine the impacts of vacancy on cell viability as nano-SARs are often determined by in silico analysis of quantitative descriptors of intrinsic properties and biological receptors acquired from sufficiently large databases of nanomaterials ${ }^{30,31}$. The vacancy densities of TMDs were assessed by surface atom ratios of $\mathrm{S} / \mathrm{Se}$ vs. W/Mo ${ }^{32,33}$. As shown in Table 1, these nanoparticles had different compositions, sizes, surface charges, and surface atom ratios. We examined the correlations between cell viabilities and physicochemical properties of TMDs. Pearson correlation analysis showed that surface atom ratio (vacancy density) had strong correlation with cell viability, displaying a correlation factor of $|\mathrm{r}|$ at 0.89 . This result indicated that surface vacancy may be the critical property dictating the ferroptosis effect induced by $\mathrm{WS}_{2}$ and $\mathrm{MoS}_{2}$ nanosheets. 
a
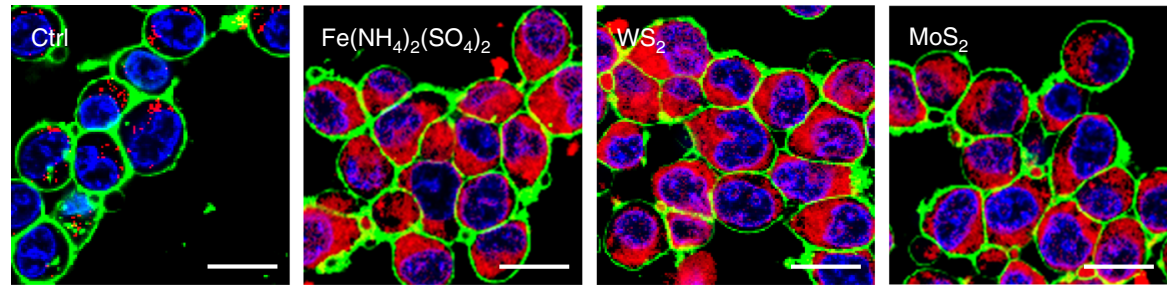

Blue: Nucleus Red: $\mathrm{Fe}^{2+}$ Green: Membrane
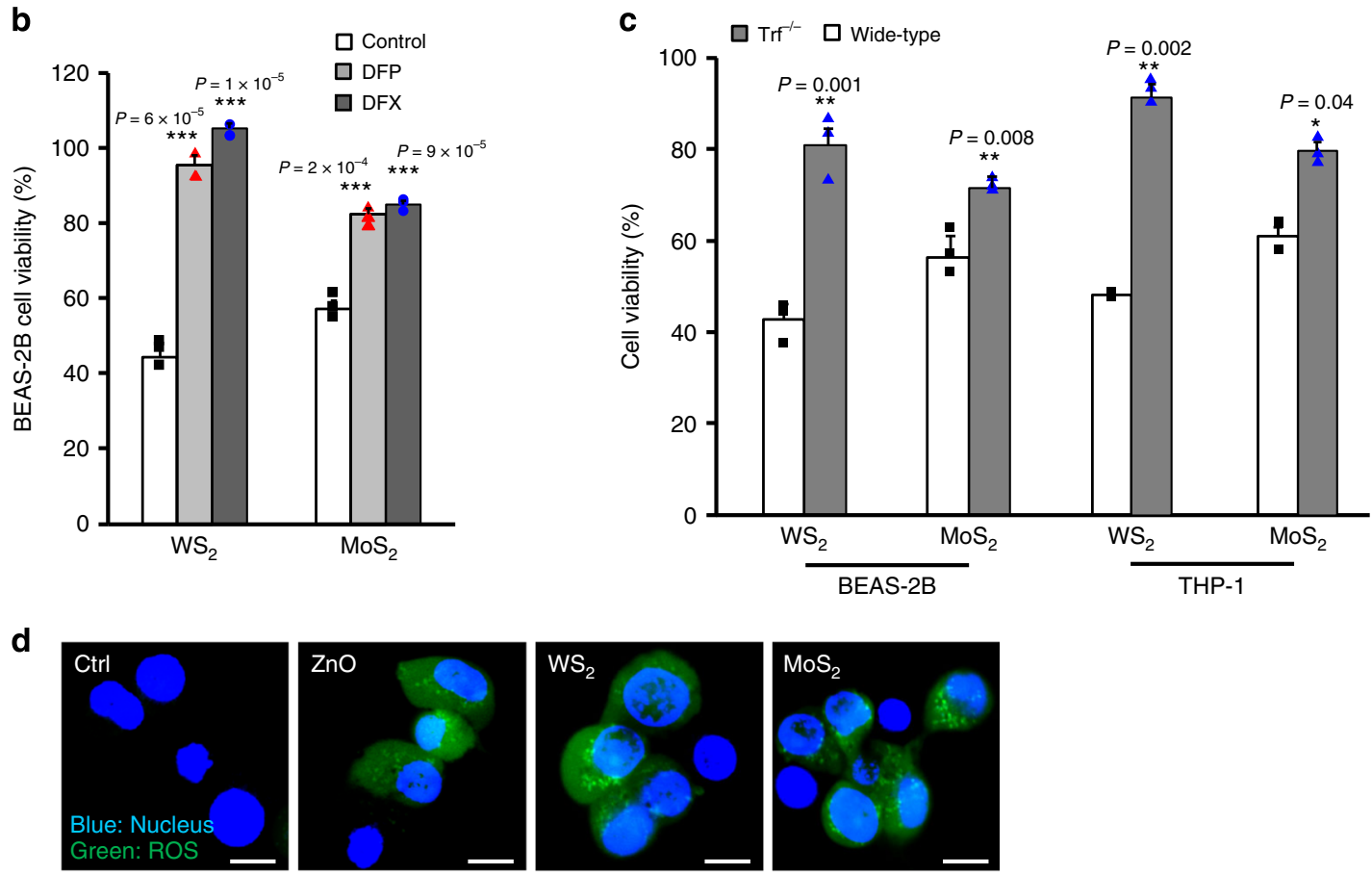

e
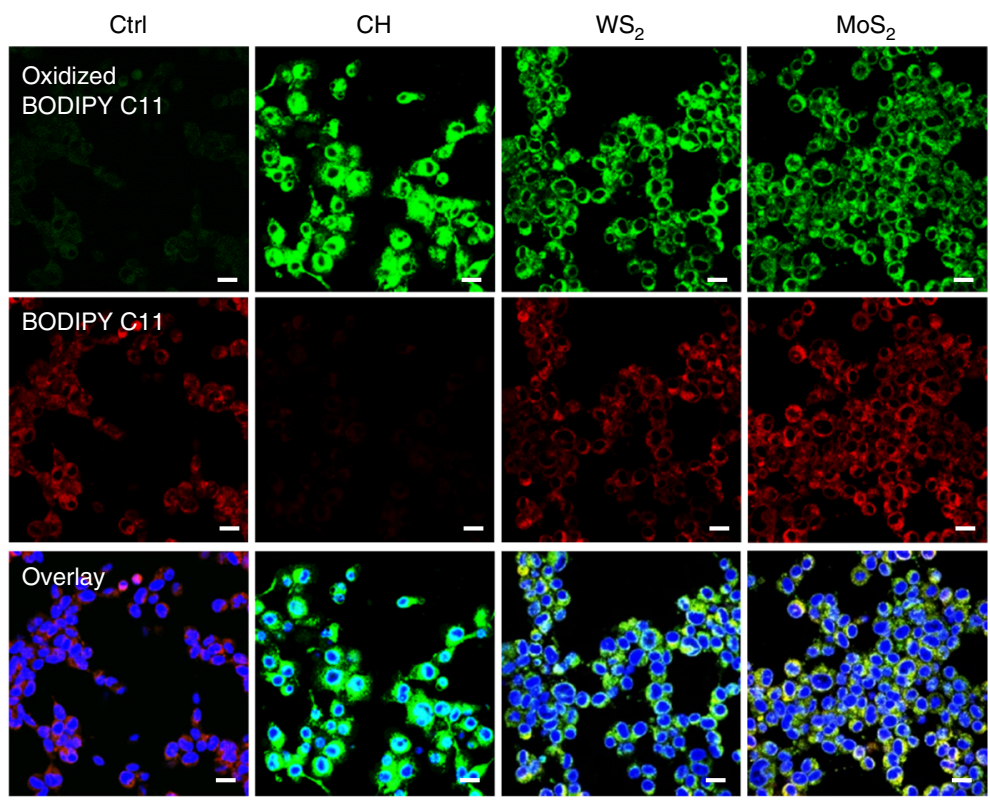

This nano-SAR information was further validated by engineering design of $\mathrm{WS}_{2} / \mathrm{MoS}_{2}$ for vacancy healing (Fig. 5a). Specifically, we found $\mathrm{Na}_{2} \mathrm{~S}$ treatment is able to reduce phospholipid-binding activity of $\mathrm{WS}_{2}$ while methanol is capable of quenching surface radicals on $\mathrm{MoS}_{2}$. These functionalized nanosheets were denoted as ss-WS $\mathrm{Wh}_{2}$ and me-MoS . We exploited high resolution (HR) TEM to visualize the vacancies on pristine and functionalized
$\mathrm{MoS}_{2}$ and $\mathrm{WS}_{2}$ nanosheets. As shown in Supplementary Fig. 7, while substantial single vacancies and linear surface vacancies could be identified on the surfaces of $\mathrm{WS}_{2}$ and $\mathrm{MoS}_{2}$ nanosheets (yellow circles), surface passivation is an effective strategy for vacancy healing. Before biocompatibility tests, we first examined whether the surface modifications may affect the lubricating properties of TMDs as they are often used as lubricant additives. 
Fig. 3 Biomarkers of ferroptosis in TMD-exposed cells. a Representative images of $\mathrm{Fe}^{2+}$ in cells by confocal microscope. BEAS-2B cells treated by $100 \mu \mathrm{M}$ $\mathrm{Fe}\left(\mathrm{NH}_{4}\right)_{2}\left(\mathrm{SO}_{4}\right)_{2}, 200 \mu \mathrm{g} / \mathrm{mL} \mathrm{WS}_{2}$ and $\mathrm{MoS}_{2}$ were stained by FeRhoNox (red) to visualize the cellular distribution of Fe ${ }^{2+}$. Hoechst 33342 and WGA were used to stain nuclei (blue) and cell membrane (green), respectively (scale bar: $10 \mu \mathrm{m}$ ). Shown are the representative images from three independent cell samples. $\mathbf{b}$ Effects of $\mathrm{Fe}^{2+}$ chelators on $\mathrm{WS}_{2}$ and $\mathrm{MoS}_{2}$ induced cytotoxicity ( $n=3$ biologically independent cell samples). BEAS-2B cells pretreated by $2 \mathrm{mM}$ DFP or $0.4 \mathrm{mM}$ DFX were exposed to $200 \mu \mathrm{g} / \mathrm{mL} \mathrm{WS}$ and $\mathrm{MoS}_{2}$ and examine cell viability after $48 \mathrm{~h}$ incubation. Data are presented as mean values \pm SD. ${ }^{* \star} p<0.001$ compared to untreated cells by two-tailored Student $t$-test. c Comparison of cell viabilities in wide-type and TfR-KD cells, cell viabilities in wide-type and TfR-KD cells exposed to $200 \mu \mathrm{g} / \mathrm{mL} \mathrm{WS} / \mathrm{MoS}_{2}$ for $48 \mathrm{~h}$ were assessed by ATP assay ( $n=3$ biologically independent cell samples). Data are presented as mean values \pm SD. ${ }^{\star \star} p<0.01,{ }^{\star \star \star} p<0.001$ compared to wide-type cells by two-tailored Student $t$-test. $\mathbf{d}$ Representative images of ROS and e lipid peroxidation in BEAS-2B cells. After 12 incubation with $200 \mu \mathrm{g} / \mathrm{mL} \mathrm{WS} \mathrm{S}_{2}$ and $\mathrm{MoS}_{2}$ for $12 \mathrm{~h}, \mathrm{BEAS}-2 \mathrm{~B}$ cells were stained with $\mathrm{H}_{2}$ DCF-DA (scale bar: $10 \mu \mathrm{m}$ ) and Image-iT lipid peroxidation staining kit (scale bar: $10 \mu \mathrm{m}$ ) for confocal observation of nuclei (blue), reduced substrate (red), and oxidized substrate (green). $10 \mu \mathrm{M} \mathrm{CH}$ were used as positive controls. Shown are the representative images from three independent cell samples.

a

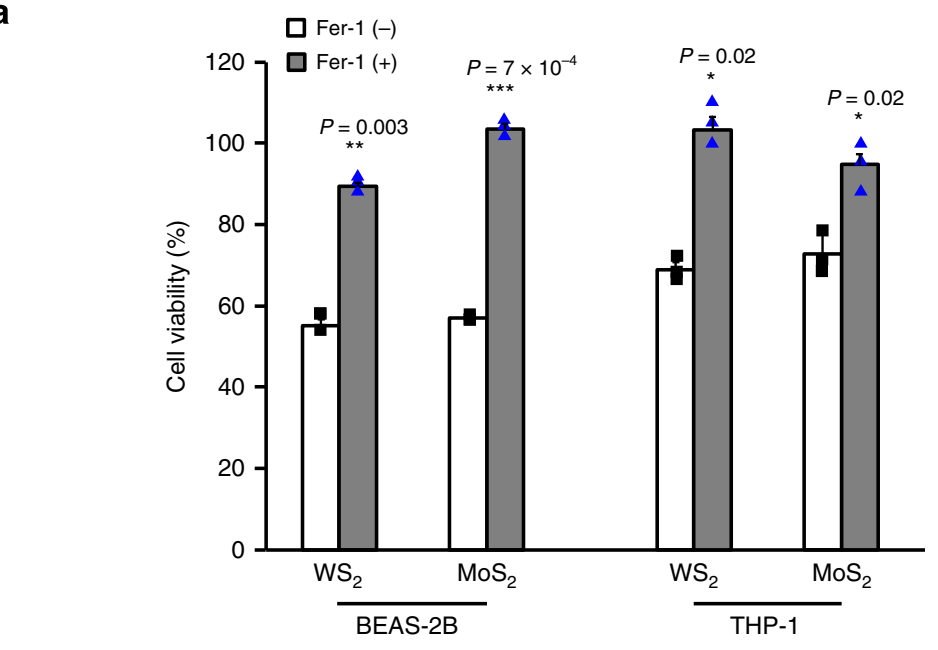

b
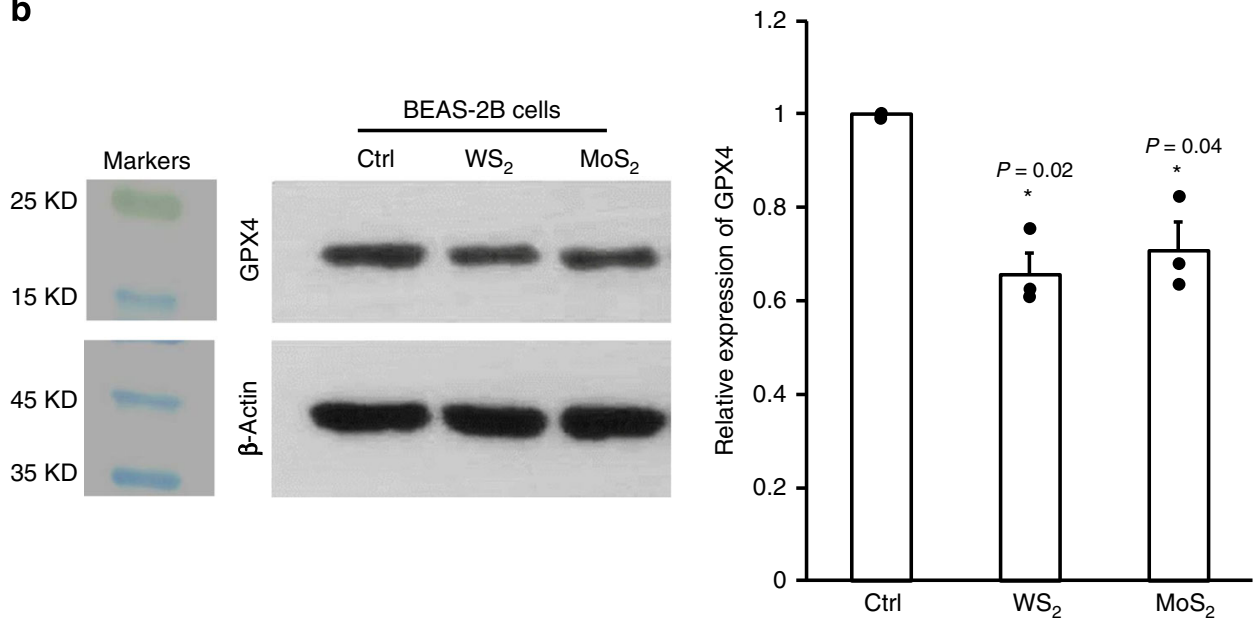

Fig. 4 Impacts of Fer-1 and GPX4 expression in TMD-treated cells. a Effects of Fer-1 on $\mathrm{MoS}_{2}$ and $\mathrm{WS}_{2}$ induced cytotoxicity ( $n=3$ biologically independent cell samples). BEAS-2B and THP-1 cells were pretreated by $10 \mu \mathrm{M} \mathrm{Fer-1}$ for $1 \mathrm{~h}$, followed by $48 \mathrm{~h}$ incubation with $200 \mu \mathrm{g} / \mathrm{mL} \mathrm{WS}_{2}$ and MoS 2 $(n=3)$. MTS assay was used to assess the impacts of Fer-1 on $\mathrm{WS}_{2} / \mathrm{MoS}_{2}$-induced cell deaths. Data are presented as mean values \pm SD. ${ }^{\star \star} p<0.01$ and ${ }^{\star \star \star} p<0.001$ compared to cells without Fer-1 pretreatment by two-tailored Student $t$-test. b Assessment of GPX4 expression in BEAS-2B cells. After exposure to $200 \mu \mathrm{g} / \mathrm{mL} \mathrm{WS}$ and $\mathrm{MoS}_{2}$ for $48 \mathrm{~h}, \mathrm{BEAS}-2 \mathrm{~B}$ cells were collected, washed and lyzed for Western blotting assay (left panel). The relative expression of GPX4 was assessed by the optical density of each band on representative Western blotting images (right panel, $n=3$ independent experiments). Data are presented as mean values \pm SD. ${ }^{*} p<0.05$, compared to Ctrl cells by two tailored Student $t$-test.

As shown in Supplementary Fig. $8, \mathrm{Na}_{2} \mathrm{~S}$ and methanol treatments had negligible effects on the friction coefficients of $\mathrm{WS}_{2}$ and $\mathrm{MoS}_{2}$, respectively. We therefore thought the surface passivation did not affect the utility of TMDs as lubricants. In addition, surface passivation could significantly reduce the interactions between $\mathrm{WS}_{2}$ and membrane lipids as well as the radicals on $\mathrm{MoS}_{2}$ surfaces (Fig. 5b and Supplementary Fig. 9). We used isolated lysosomes from BEAS- $2 \mathrm{~B}$ cells to examine the oxidation capability of $\mathrm{MoS}_{2}$ and me-MoS 2 by the lipid peroxidation staining kit. As shown in Supplementary Fig. 10, $\mathrm{MoS}_{2}$ induced significant oxidation of isolated lysosomes emitting strong fluorescence of oxidized BODIPY 581/591 C11, whereas surface passivation could fully ameliorate this effect. Biocompatibility test in cells showed that the modified nanosheets had similar cellular uptake to pristine TMDs (Supplementary Fig. 11), but less effects on lysosomal damage evidenced by diminishing 
Table 1 Correlation analysis between cell viability and physicochemical property.

\begin{tabular}{|c|c|c|c|c|c|c|c|}
\hline \multirow[t]{2}{*}{ TMD } & & \multicolumn{5}{|c|}{ Physicochemical properties } & \multirow[t]{2}{*}{ Cell viability (\%) } \\
\hline & & Thickness (nm) & Diameter (nm) & Hydrodynamic size $(\mathrm{nm})$ & Zeta potential $(\mathrm{nm})$ & Surface atom ratio ${ }^{a}$ & \\
\hline \multirow{5}{*}{$\mathrm{WS}_{2}$} & 1 & $211 \pm 8$ & $384 \pm 9$ & $189.7 \pm 0.4$ & $-20.7 \pm 0.4$ & 1.77 & 108.4 \\
\hline & 2 & $90 \pm 3$ & $178 \pm 5$ & $139.5 \pm 3.2$ & $-24.5 \pm 1.5$ & 1.82 & 117.4 \\
\hline & 3 & $40 \pm 2$ & $108 \pm 3$ & $120.2 \pm 0.4$ & $-24.7 \pm 1.3$ & 1.75 & 108.7 \\
\hline & 4 & $2 \pm 1$ & $10 \pm 2$ & $94 \pm 2$ & $-6 \pm 0.3$ & 1.21 & 54.6 \\
\hline & 5 & $2 \pm 1$ & $12 \pm 1$ & $96 \pm 1$ & $-7.2 \pm 2$ & 1.77 & 89.2 \\
\hline \multirow[t]{5}{*}{$\mathrm{MoS}_{2}$} & 1 & $153 \pm 6$ & $407 \pm 2$ & $308.7 \pm 1.8$ & $-25.4 \pm 1.2$ & 1.71 & 113.9 \\
\hline & 2 & $79 \pm 3$ & $199 \pm 5$ & $143.9 \pm 0.2$ & $-24.8 \pm 0.8$ & 1.70 & 114.2 \\
\hline & 3 & $49 \pm 3$ & $175 \pm 1$ & $115.3 \pm 0.9$ & $-27.5 \pm 0.4$ & 1.53 & 91.5 \\
\hline & 4 & $3 \pm 1$ & $9 \pm 3$ & $91 \pm 1$ & $-18.6 \pm 0.3$ & 1.31 & 57.3 \\
\hline & 5 & $3 \pm 1$ & $10 \pm 2$ & $93 \pm 2$ & $-17.5 \pm 1.0$ & 1.65 & 101.2 \\
\hline \multirow[t]{5}{*}{$\mathrm{WSe}_{2}$} & 1 & $202 \pm 8$ & $304 \pm 6$ & $204 \pm 4$ & $-20.7 \pm 0.4$ & 1.65 & 105.3 \\
\hline & 2 & $140 \pm 4$ & $92 \pm 2$ & $146 \pm 4$ & $-27.8 \pm 0.7$ & 1.71 & 116.9 \\
\hline & 3 & $42 \pm 8$ & $78 \pm 4$ & $150 \pm 5$ & $-20.3 \pm 0.2$ & 1.60 & 99.9 \\
\hline & 4 & $16 \pm 4$ & $62 \pm 6$ & $106 \pm 0.5$ & $-23.5 \pm 0.1$ & 1.61 & 96.2 \\
\hline & 5 & $2 \pm 1$ & $14 \pm 3$ & $94 \pm 1$ & $-24.2 \pm 0.3$ & 1.64 & 99.4 \\
\hline \multirow[t]{5}{*}{$\mathrm{MoSe}_{2}$} & 1 & $160 \pm 2$ & $232 \pm 2$ & $349 \pm 9$ & $-21.5 \pm 0.3$ & 1.73 & 100.5 \\
\hline & 2 & $91 \pm 7$ & $113 \pm 9$ & $152 \pm 1$ & $-20.9 \pm 0.1$ & 1.80 & 112.9 \\
\hline & 3 & $39 \pm 7$ & $73 \pm 9$ & $145 \pm 3$ & $-20.4 \pm 0.2$ & 1.81 & 115.3 \\
\hline & 4 & $21 \pm 4$ & $50 \pm 1$ & $120 \pm 5$ & $-20.2 \pm 0.2$ & 1.71 & 98.4 \\
\hline & 5 & $2 \pm 1$ & $16 \pm 4$ & $123 \pm 2$ & $-18.7 \pm 0.4$ & 1.68 & 92.8 \\
\hline \multicolumn{2}{|c|}{ Correlation factor } & 0.51 & 0.48 & 0.38 & -0.64 & 0.89 & NA \\
\hline
\end{tabular}

aRepresents the ratio of S/Se vs. W/Mo determined by X-ray photoelectron spectroscopy (XPS). Cell viability data were acquired in BEAS-2B cells exposed to $200 \mu \mathrm{g} / \mathrm{mL}$ for $48 \mathrm{~h}$ by MTS assay. Data are presented as mean values \pm SD. Replicate numbers: thickness $(n=50)$, diameter $(n=50)$, hydrodynamic size $(n=10)$, Zeta potential $(n=10)$, surface atomic ratio $(n=3)$, and cell viability $(n=3)$.

$\mathrm{Fe}^{2+}$ release in cytoplasm (Fig. 5c) as well as ferroptotic cell deaths (Fig. 5d). All these results well demonstrate our hypothesis on the role of surface vacancies in TMD-induced ferroptosis. The $\mathrm{Na}_{2} \mathrm{~S}$ and methanol treatments could be considered as safe design approaches for $\mathrm{WS}_{2}$ and $\mathrm{MoS}_{2}$ nanosheets because these passivation methods could significantly reduce the cytotoxic effects of two nanosheets without affecting their utilities as lubricants.

Validation of TMD-induced ferroptosis in vivo. The ferroptosis effects as well as the identified nano-SAR were finally validated in animals. From the perspective of inhalation exposure risks of 2D TMDs in real scenarios, we examined the pulmonary toxicity of $\mathrm{WS}_{2}, \mathrm{MoS}_{2}, \mathrm{MoSe}_{2}, \mathrm{ss}-\mathrm{WS}_{2}$, and me- $\mathrm{MoS}_{2}$ by oropharyngeal aspiration. Quartz was included as a positive control. Following $40 \mathrm{~h}$ exposure, mice were sacrificed to collect bronchoalveolar lavage fluid (BALF) to examine the effects of TMDs on cells and cytokines. First of all, we examined GPX4 expression, lysosomal release of $\mathrm{Fe}^{2+}$ and lipid peroxidation to validate the ferroptosis mechanism. As shown in Fig. 6a, reduction of GPX4 was identified in alveolar macrophages extracted from animal lungs exposed to $\mathrm{WS}_{2}$ nanosheets. Meanwhile, $\mathrm{WS}_{2}$ treatments led to significant $\mathrm{Fe}^{2+}$ leakage in alveolar macrophages by FeRhoNox-1 staining, displaying diffused red fluorescence in whole cytoplasm (Fig. 6b). Subsequently, the released $\mathrm{Fe}^{2+}$ could elicit lipid peroxidation, evidenced by a majority of alveolar macrophages displaying strong green fluorescence of oxidized BODIPY C11 (Fig. 6c). Notably, Fer-1 treatment could ameliorate the impacts of $\mathrm{WS}_{2}$ on GPX4 expression, and suppressed lysosomal release of $\mathrm{Fe}^{2+}$ and lipid peroxidation in alveolar macrophages. Surface passivation could also attenuate these key signals of ferroptosis in alveolar macrophages (Supplementary Fig. 12). These data showed that the impact of the TMDs on pulmonary alveolar macrophages duplicated the results seen in tissue culture cells.

We also questioned whether the ferroptosis effect of TMDs would result in pro-inflammatory effects in mouse lungs. As shown in Fig. 7a, quartz and pristine TMDs induced significantly higher levels of neutrophil recruitment in BALF, compared to the neutrophil counts in ss- $\mathrm{WS}_{2}$ and me- $\mathrm{MoS}_{2}$ treatments. The proinflammatory response of pristine TMDs in the BALF was reflected in the increases of cytokines including LIX, TNF- $\alpha$, and IL-1 $\beta$. By contrast, surface passivation could significantly reduce the inflammatory cytokine production (Fig. 7b). Consistently, while me- $\mathrm{MoS}_{2}$ and ss- $\mathrm{WS}_{2}$ exhibited negligible inflammatory effects in focal pulmonary infiltrates by hematoxylin and eosin (H\&E) staining, pristine $\mathrm{MoS}_{2}$ and $\mathrm{WS}_{2}$ elicited significant lung inflammation, displaying increased nucleus densities due to immune cell recruitments (Fig. 7c). All these animal results well confirmed our in vitro findings.

\section{Discussion}

2D TMDs consist of a monolayer or few-layer covalently bonded chalcogen and metal atoms. Unlike $2 \mathrm{D}$ graphene materials, the transition metal and dichalcogenide atoms of TMDs possess abundant electrons in $d$ or $f$ orbitals, which may confer intriguing surface properties, such as high photoluminescence quantum yield ${ }^{34,35}$, sizeable bandgap ${ }^{36,37}$, valley-selective circular dichroism $^{38,39}$ and strong photocurrent responses ${ }^{40,41}$. The industrial uses of 2D TMDs have led to increasing exposure risks to humans as well as substantial concerns on their biosafety. Since 2D TMD materials have exhibited many intriguing surface chemistries and justified their potential applications in many fields, their interactions with biological systems have been underlined ${ }^{42}$. We therefore proposed this study to investigate the hazard effects and nano-SARs of TMDs in mammalian cells. Compared to other nano-bio studies on 2D TMDs, our study made two findings: (i) $\mathrm{MoS}_{2}$ and $\mathrm{WS}_{2}$ were able to induce ferroptosis in cells and animal lungs; (ii) the vacancy on nanosheet surfaces was responsible for the ferroptosis cell deaths. Beside of the direct impacts of surface vacancy on cell viability, inhaled TMD nanosheets may escape the clearance by mucociliary escalator, deposit in pulmonary alveoli and interact with lung surfactants and proteins to form biocorona structures ${ }^{43}$. The adsorption of immunoglobulins, complement factors, lipids and coagulation proteins on TMD surfaces 
a<smiles>CB1C(C)C[C@H](C)N(C)B(C)N1C</smiles>

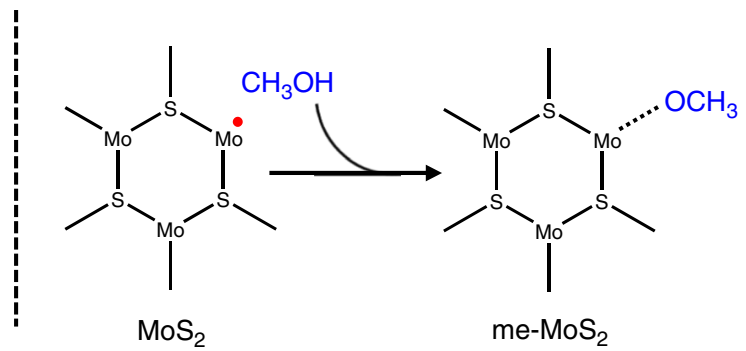

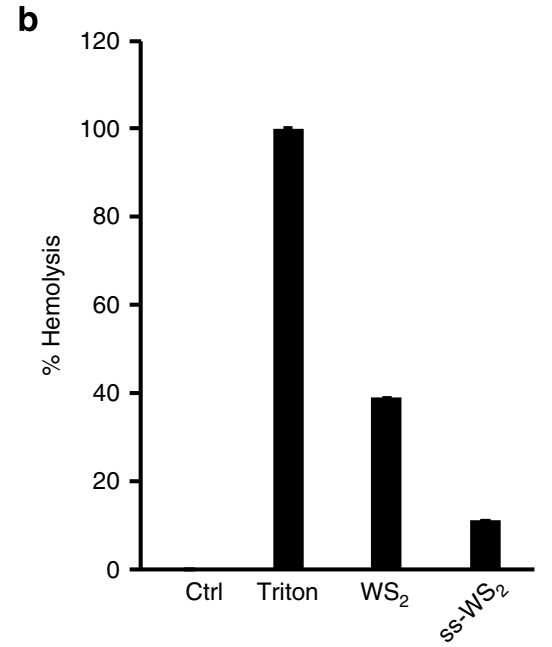

C

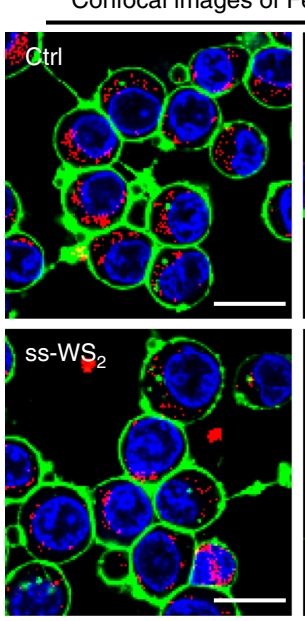

Blue: Nucleus Red: Fe

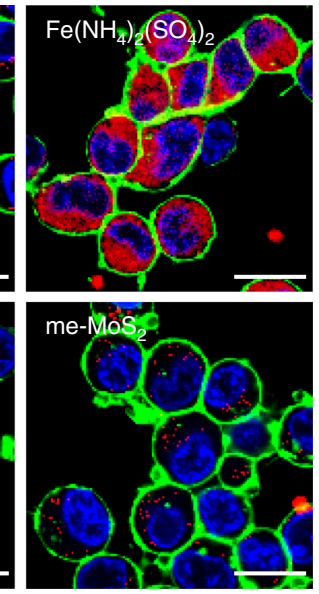

Green: Membrane

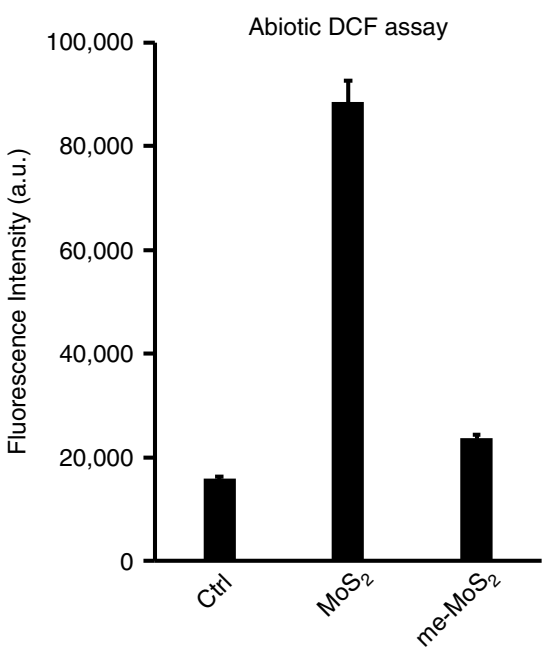

d

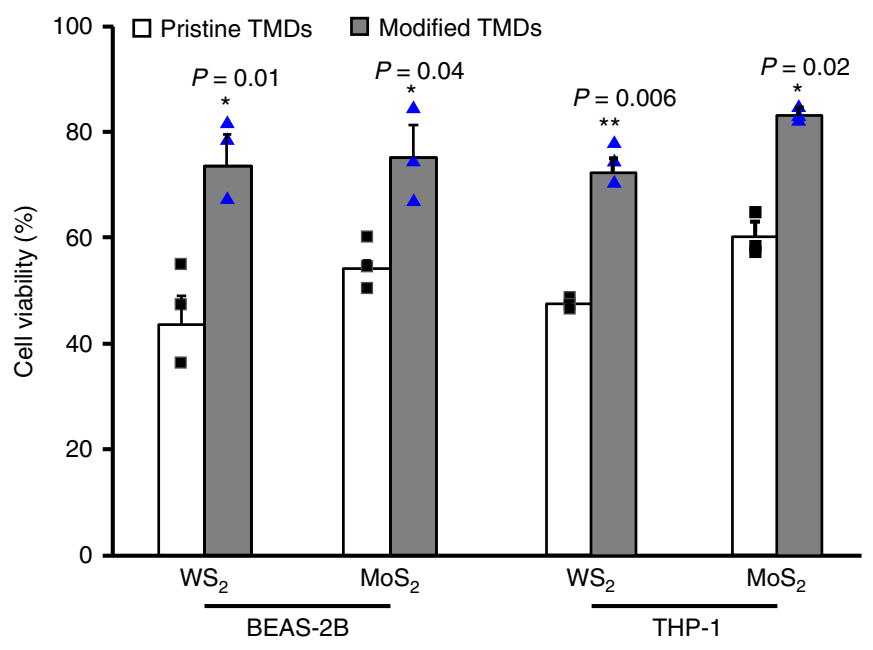

Fig. 5 Safe design of $\mathbf{W S}_{\mathbf{2}}$ and $\mathbf{M o S}_{\mathbf{2}}$ by surface passivation. a Schematic images to passivate nanosheet surfaces. $\mathbf{b}$ Assessment of surface passivation by hemolysis or abiotic DCF assay ( $n=3$ independent experiments). Data are presented as mean values \pm SD. $\mathbf{c}$ Representative images of lysosomal release of $\mathrm{Fe}^{2+}$ and $\mathbf{d}$ cell viability test in cells exposed to modified TMDs. To assess the impacts of surface passivation, BEAS-2B and THP-1 cells were exposed to $200 \mu \mathrm{g} / \mathrm{mL}$ nanosheets for $48 \mathrm{~h}$. The treated cells were subject to MTS assay or FeRhoNox staining for confocal imaging ( $n=3$ biologically independent cell samples). Scale bar represents $10 \mu \mathrm{m}$. Cell viability data are presented as mean values \pm SD. ${ }^{\star} p<0.05,{ }^{\star \star} p<0.01$ compared to the pristine TMD-treated cells by two-tailored Student $t$-test.

may lead to the recognition and capture by immune cells in vivo, eliciting rapid clearance, and significant immunotoxicity ${ }^{44,45}$. In contrast, formation of protein corona in vitro may reduce the cellular internalization of nanoparticles and ameliorate cytotoxicity due to improved biocompatibility 43,46 .

Recently, a few routine hazard signals widely reported in a majority of engineered nanomaterials have been identified in TMD-treated cells or animals. For instance, $\mathrm{MoS}_{2}$ nanosheets were found to induce reactive oxidative species and cell deaths in
A549 cells ${ }^{8}$. After exposure to animal lungs, $\mathrm{MoS}_{2}$ nanosheets induced inflammatory cytokine (IL-8, TNF- $\alpha$, and IL-1 $\beta$ ) production in bronchoalveolar lavage fluids ${ }^{9}$. In contrary of these toxicity reports, McManus et al. found that water-based $\mathrm{MoS}_{2}$ and $\mathrm{WS}_{2}$ nanosheets induced little cytotoxicity in A549 and HaCat cells ${ }^{10}$. The differences of material source, physicochemical properties of TMDs, exposure time, doses and routes may be responsible for the conflict reports. Wang et al. used same cell lines (THP-1 and BEAS-2B) to us for cytotoxicity assessments 
a

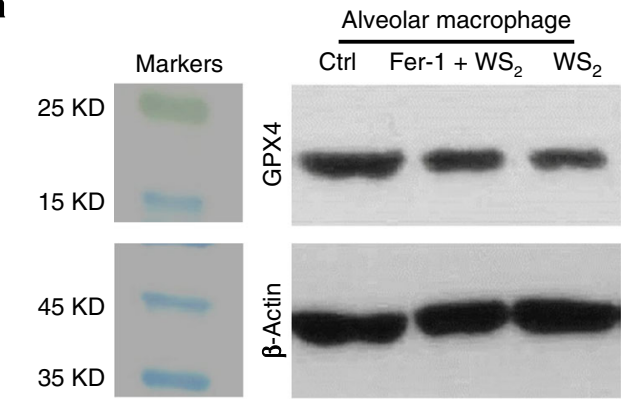

b

Confocal imaging of $\mathrm{Fe}^{2+}$ in alveolar macrophages

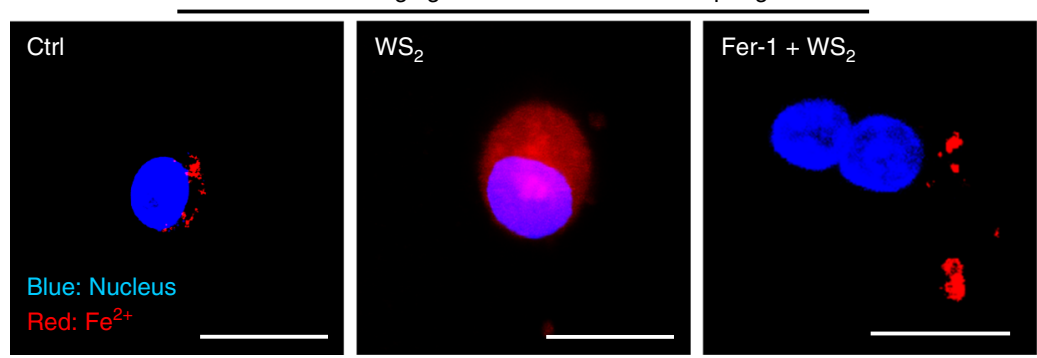

C

Lipid peroxidation imaging in alveolar macrophage

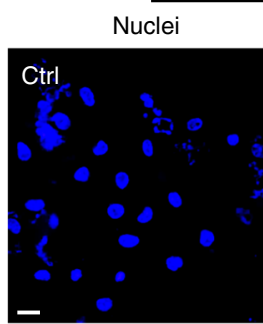

BODIPY C11
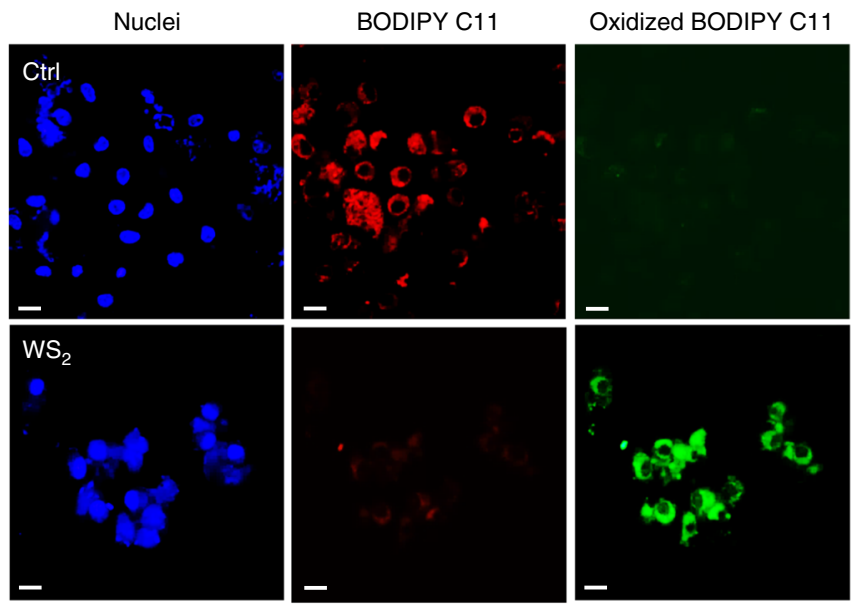

Overlay
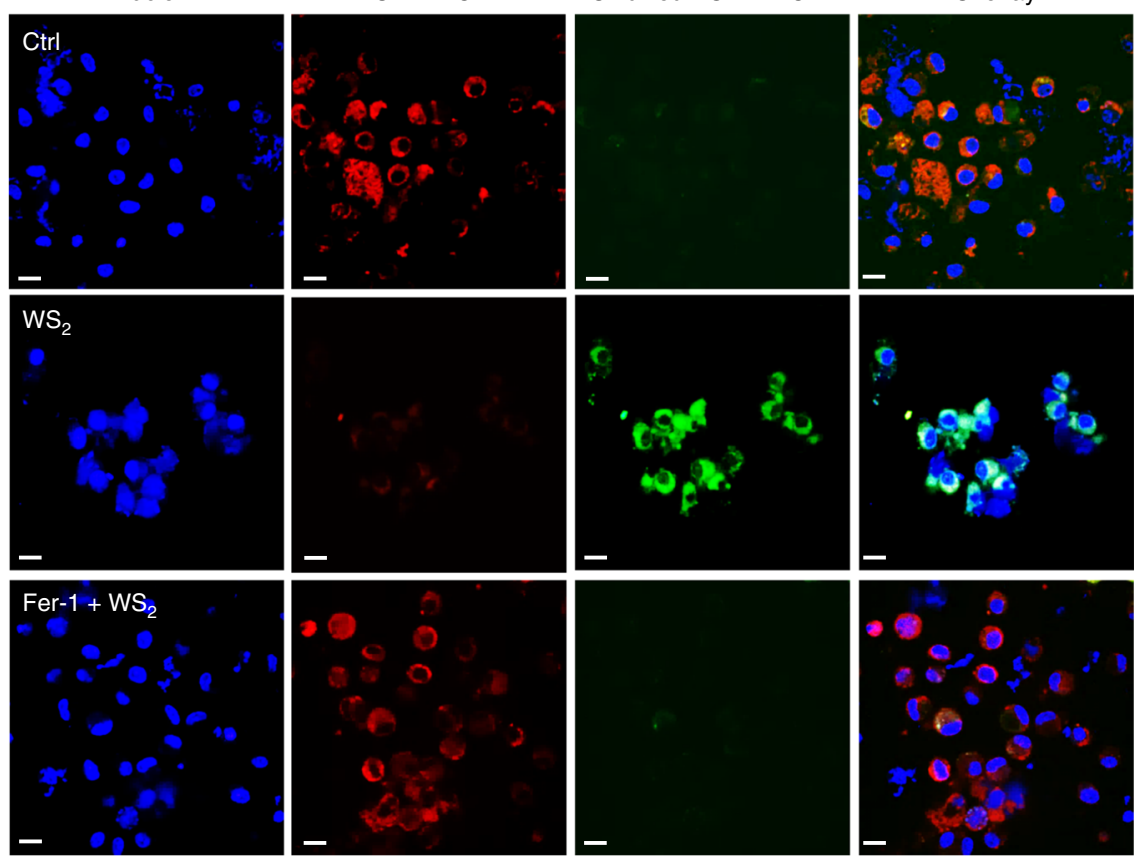

Fig. 6 Validation of ferroptosis in alveolar macrophages from lung tissue. a Representative Western blotting images of GPX4 from three independent experiments, $\mathbf{b}$ representative images of lysosomal release of $\mathrm{Fe}^{2+}$, and $\mathbf{c}$ lipid peroxidation in alveolar macrophages from four independent views. Animals pretreated with or without $50 \mu \mathrm{g} / \mathrm{Kg}$ Fer- 1 for $2 \mathrm{~h}$ were exposed to $1 \mathrm{mg} / \mathrm{Kg} \mathrm{WS}$ for $40 \mathrm{~h} \mathrm{(} n=6$ mice). Then the BALF of animals were collected to extract alveolar macrophages. The cells were divided into three portions. One was lysed for Western blotting analysis, and the other two were stained by Image-iT lipid peroxidation staining kit (scale bar: $10 \mu \mathrm{m}$ ) to visualize nuclei (blue), reduced substrate (red) and oxidized substrate (green), or FeRhoNox-1 (scale bar: $10 \mu \mathrm{m}$ ) to observe lysosomal release of $\mathrm{Fe}^{2+}$.

and found limited cell viability changes at $24 \mathrm{~h}$ incubation with $0-50 \mu \mathrm{g} / \mathrm{mL} \mathrm{MoS}_{2}$ nanosheets ${ }^{9}$, whereas we merely observed significant cytotoxicity at $48 \mathrm{~h}$ incubation with $50-200 \mu \mathrm{g} / \mathrm{mL}$ $\mathrm{MoS}_{2}$ nanosheets, indicating that the exposure time and doses of TMDs may greatly affect their cytotoxicity. In terms of the impacts of exposure routes, Mei et al. study showed that intravenous injected $\mathrm{MoS}_{2}$ elicited more toxicity than intraperitoneal and intragastric administration ${ }^{11}$. Under similar doses, same exposure time, and route, we and Wang et al. discovered similar pulmonary inflammation effects for $\mathrm{MoS}_{2}$ nanosheets ${ }^{9}$. Besides, consistent with our nano-SAR findings, the surface chemistry of TMDs may play a major role in their toxicities, evidenced by the increased biocompatibility of $\mathrm{MoS}_{2}$ nanosheets functionalized by Pluronic $127^{47}$, Pluronic $87^{9}$ and PEG molecules ${ }^{48}$.

According to lifecycle analysis of nanoproducts ${ }^{11}$, fine particles may be released into environments during the fabrication, 
a

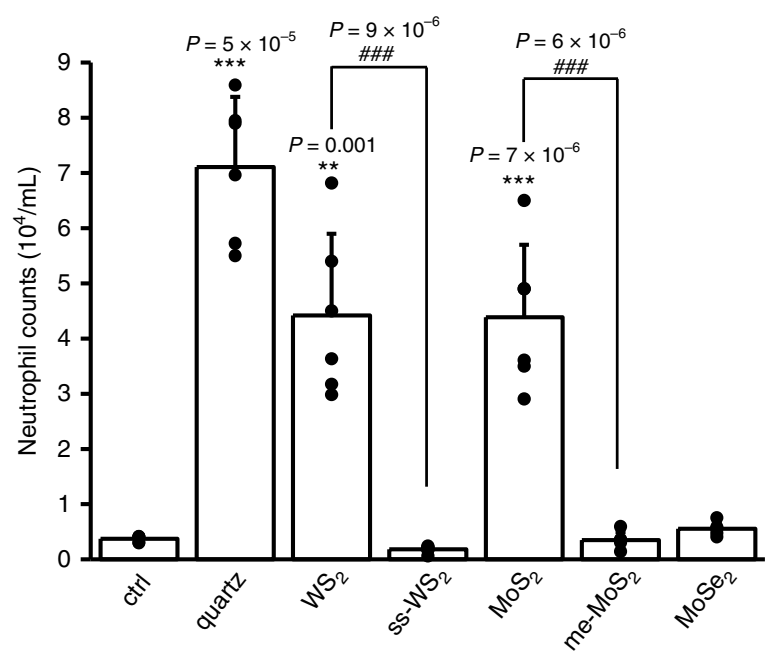

b
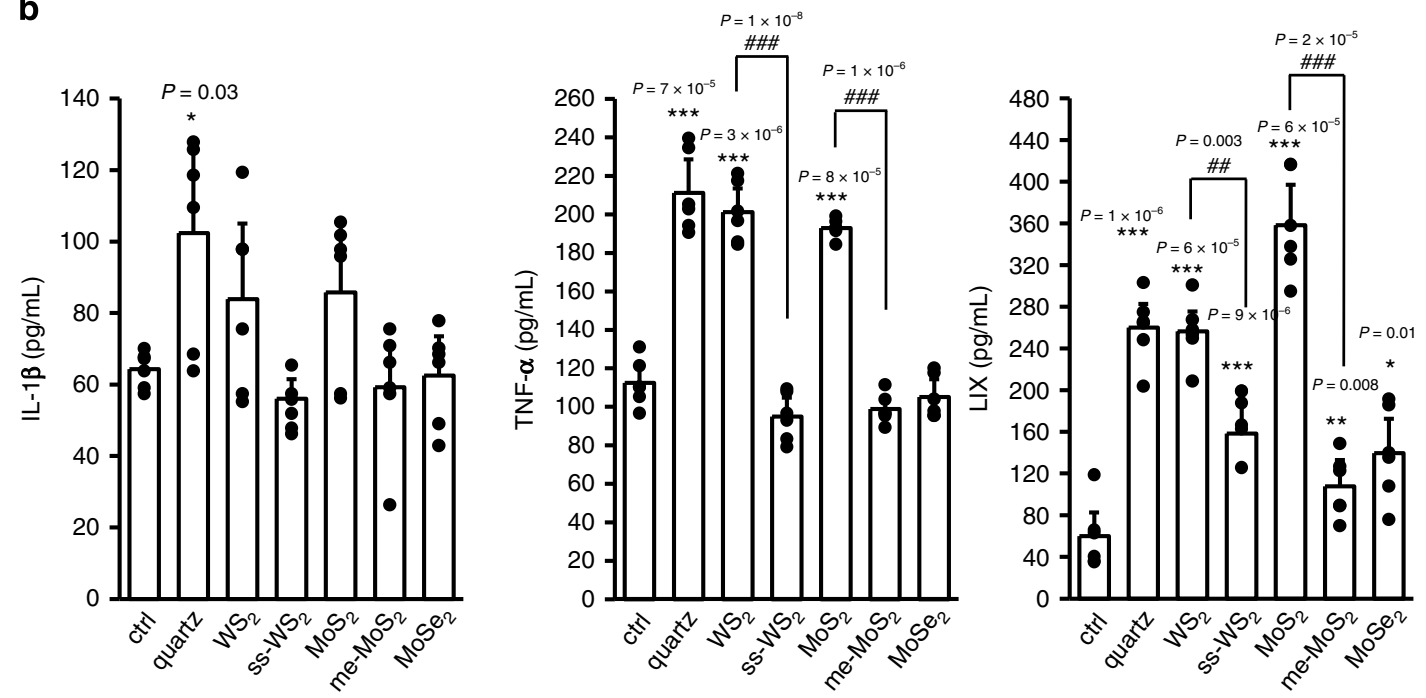

C

H\&E staining of lung tissue

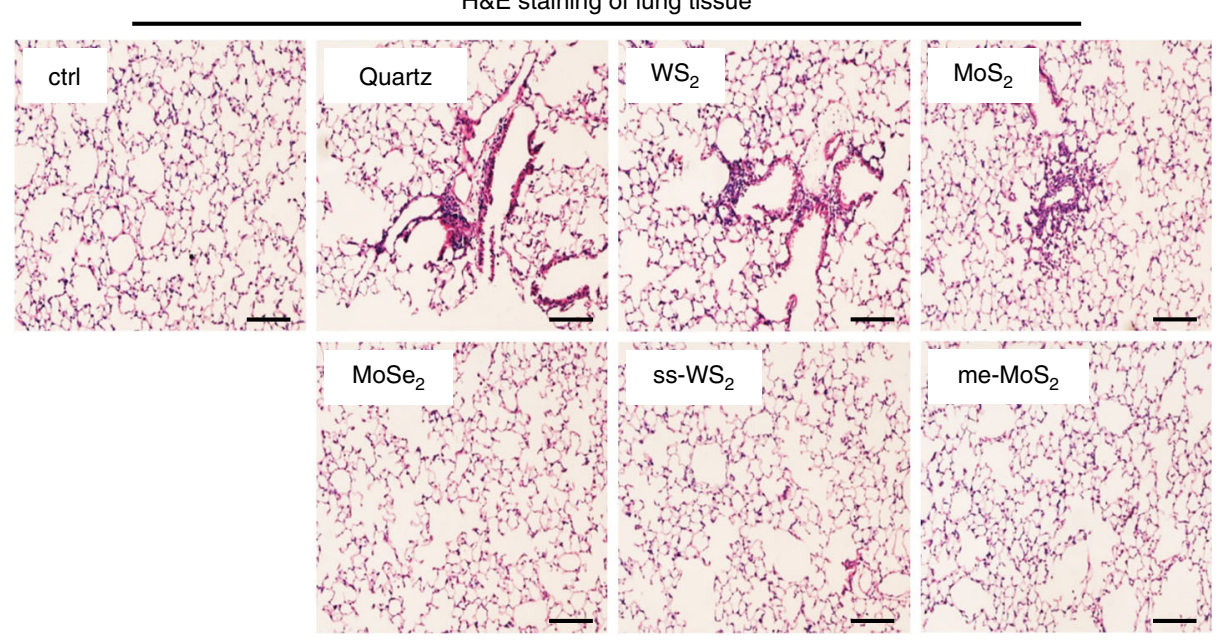

Fig. 7 Assessment of the effects of surface passivation in mouse lungs. a Neutrophil counts in BALF. Animals were exposed to $1 \mathrm{mg} / \mathrm{Kg}$ pristine or surface modified TMDs by oropharyngeal aspiration ( $n=6$ mice). After $40 \mathrm{~h}$, the animals were sacrificed and alveolar macrophages in BALF of mouse lungs were collected for overnight incubation. Immune cells in BALF were concentrated on glass slides by cytospin, fixed and stained by Quick-Diff for cell counting. Neutrophil count data are presented as mean values \pm SD. b Pro-inflammatory cytokine production in BALF and $\mathbf{c}$ representative H\&E staining images of lung tissues from six biologically independent samples (scale bar: $100 \mu \mathrm{m}$ ). Pro-inflammatory cytokines were determined by ELISA. Cytokine

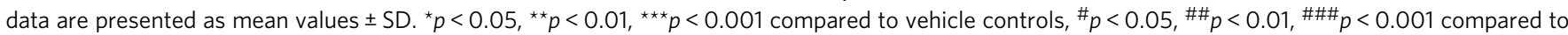
$\mathrm{WS}_{2}$ and $\mathrm{MoS}_{2}$ by two-tailored Student $t$-test. 
transportation, consumption and recycling of nanoproducts. The particulates have shown high inhalation exposure risk and are capable of passing through blood-air barrier to induce severe pulmonary diseases ${ }^{43}$, such as inflammation, fibrosis, pneumoconiosis or chronic obstructive pulmonary disease. Since TMDs are popularly used as lubricants in industries and daily life, the fine particulates of TMDs in aerosols have high risks of inhalation exposure. The OSHA permissible exposure thresholds for soluble and insoluble molybdenum materials in workroom air are set at 5 and $15 \mathrm{mg} / \mathrm{m}^{3}$, respectively ${ }^{49}$. Based on a calculation approach being used at $\mathrm{NIOSH}^{50}$, we could estimate that a worker exposure to $15 \mathrm{mg} / \mathrm{m}^{3}$ TMDs for $8 \mathrm{~h}$ /day over a five-month time period over a 5-year working time could lead to a lung burden of 1.875 $\mathrm{mg} / \mathrm{m}^{2}$. Considering that a bolus exposure of $1 \mathrm{mg} / \mathrm{Kg}$ in the mouse is equivalent to $0.5 \mathrm{mg} / \mathrm{m}^{2}$ of nanoparticle exposure in mouse lungs, oropharyngeal aspiration of $0-3.6 \mathrm{mg} / \mathrm{Kg}$ TMDs in mice is comparable to the real exposure levels of TMDs in workroom air. Assuming a homogeneous distribution of TMD in tissue culture dish and $10 \mu \mathrm{m}$ thickness of cell layer ${ }^{49}$, the corresponding in vitro TMD dose would be $0-187.5 \mu \mathrm{g} / \mathrm{mL}$. Overall, the in vitro $(0-200 \mu \mathrm{g} / \mathrm{mL})$ and in vivo $(1 \mathrm{mg} / \mathrm{Kg})$ doses used in this study is relevant to the possible occupational exposure in real scenarios. $\mathrm{MoS}_{2}$ and $\mathrm{WS}_{2}$ induced ferroptosis in alveolar macrophages and acute inflammation in lung tissues after $40 \mathrm{~h}$ exposure. The identified nano-SAR in cells could be wellvalidated in mouse lungs, and facilitate the safe design of TMD derivatives. Since U.S. FDA and Organisation for Economic Cooperation and Development have released strict guidance for the safety evaluation of nanoproducts ${ }^{50}$, the nano-SAR based safe design approach may greatly improve the sustainable development of TMD-based nanotechnology.

In summary, our study defined a TMD-induced ferroptosis effect in mammals. The ferroptosis pathway involved endocytosis of TMD nanosheets into lysosomes, GPX4 reduction, ferrous ion release, ROS generation, lipid peroxidation and cell death. Surface vacancies on $\mathrm{WS}_{2}$ and $\mathrm{MoS}_{2}$ nanosheets were responsible for ferroptosis effects. $\mathrm{Na}_{2} \mathrm{~S}$ and methanol treatments were able to passivate particle surfaces, prevent lysosomal release of $\mathrm{Fe}^{2+}$ into cytoplasm and therefore protect cells. These in vitro findings could be validated in animal lungs by oropharyngeal aspiration of TMD suspensions. $\mathrm{WS}_{2}$ and $\mathrm{MoS}_{2}$ nanosheets induced ferroptosis in alveolar macrophages, pro-inflammatory cytokine production in BALF and focal inflammation around airways, whereas surface passivation could dramatically reduce these hazard effects. The discovery of TMD-induced ferroptosis as well as related nanoSARs may greatly facilitate the safe design of TMD nanoproducts as lubricants.

\footnotetext{
Methods

Source of materials. Bulk 2D nanomaterials were purchased from Alfa Aesar (Ward Hill, MA, USA); lysosome isolation kit, ferostatin-1, Pluronic F68, iodixano (60\% w/v), cytochalasin D, NAC, FITC labeled bovine serum albumin (FITC-BSA) and DOX were purchased from Sigma-Aldrich (St. Louis, Mo, USA); MTS and ATP assay kits were purchased from Promega (Madison, WI, USA); LysoTracker ${ }^{\text {th }}$ Red DND-99, Hoechst 33342, $\mathrm{H}_{2}$ DCF-DA, lipid peroxidation kit, LIVE/DEAD staining kit and wheat germ agglutinin (WGA) were purchased from Thermo Fisher Scientific (Grand Island, NY, USA); FeRhoNox ${ }^{\mathrm{TM}_{-}} 1$ was purchased from Goryo Chemical (Chuo-ku, Tokyo, Japan); $\mathrm{Na}_{2} \mathrm{~S}$ was purchased from Aladdin (Shanghai, China); ELISA kits for detection of IL-1 $\beta$ and TNF- $\alpha$ were purchased from BD biosciences (San Jose, CA, USA); LIX ELISA kit was purchased from R\&D (Minneapolis, MN, USA); Anti-GPX4, CHX, Z-VAD-FMK and Nec-1 were purchased from Abcam (Cambridge, MA, USA); DFP and DFX were purchased from Cayman Chemical (Ann Arbor, MI, USA); Quick-Diff staining kit was purchased from Yeasen Biotechnology (Shanghai, China); 1,2-distearoyl-sn-glycero-3-phosphocholine (DSPC) was purchased from Avanti Polar Lipids (Alabaster, Alabama, USA); RIPA lysis buffer was purchased from Beyotime (Shanghai, China); ECL hypersensitive chemiluminescence solution was purchased from BOSTER (Wuhan, China); SPA, pMD and pLKO (wide-type Trfe control) plasmids, and shRNA
} transfectants of target genes (Trfc1, Trfc2) were supplied by Dr. Sijin Liu at the
Research Center for Eco-Environmental Sciences, Chinese Academy of Sciences, Beijing, China.

Synthesis of 2D nanomaterials. 2D nanomaterials were prepared by a reported method with a little modification ${ }^{51}$. In detail, $5 \mathrm{~g}$ of each bulk material was added into a glass flask with $350 \mathrm{~mL}$ of $2 \% \mathrm{w} / \mathrm{v}$ Pluronic F68 (PF-68) aqueous solution and dispersed by an ultrasonication equipped with a 0.125 -inch probe at an operation power of $60 \mathrm{~W}$ ( $30 \mathrm{~s}$ on, $5 \mathrm{~s}$ off) for $6 \mathrm{~h}$ in an ice water bath. The resulted TMD suspensions $(32 \mathrm{~mL})$ were added into $6 \mathrm{~mL}$ iodixanol $(60 \% \mathrm{w} / \mathrm{v})$, then the deposits were consecutively collected by centrifuged (Allegra 64 R, Beckman, USA) at 2000, 4000 and $8000 \mathrm{rpm}$ for $30 \mathrm{~min}$, and denoted as TMD-1, TMD-2 and TMD-3 (Table 1). The supernatants $(25 \mathrm{~mL})$ acquired at $8000 \mathrm{rpm}$ were transferred into polycarbonate tubes (Catalog: 355618, Beckman, USA) and collected the pellets by ultracentrifugation (Optima L-100XP, Beckman, USA) equipped with a $70 \mathrm{Ti}$ rotor at 25,000 rpm $\left(\mathrm{MoSe}_{2}-4\right.$ and $\left.\mathrm{WSe}_{2}-4\right)$ 50,000 rpm $\left(\mathrm{MoS}_{2}-4, \mathrm{WS}_{2}-4\right.$, $\mathrm{MoSe}_{2}-5$, and $\left.\mathrm{WSe}_{2}-5\right)$ for $15 \mathrm{~min}$. $\mathrm{MoS}_{2}-5\left(\mathrm{me}-\mathrm{MoS}_{2}\right)$ and $\mathrm{WS}_{2}-5$ (ss-WS $\mathrm{WS}_{2}$ ) were acquired by centrifugation after $24 \mathrm{~h}$ reaction of $0.5 \mathrm{mg} / \mathrm{mL} \mathrm{MoS}_{2}-4$ and $\mathrm{WS}_{2}-4$ in methanol and $30 \mathrm{mM} \mathrm{NaS}_{2}$, respectively at $37^{\circ} \mathrm{C}$ in a shaking incubator $(100 \mathrm{rpm})$. FITC-labeled $\mathrm{WS}_{2}$ and $\mathrm{MoS}_{2}$ nanosheets were synthesized by a carboxyl-amine coupling reaction ${ }^{6}$. In detail, EDC $(5 \mathrm{mg})$, NHS $(10 \mathrm{mg})$ and $5 \mathrm{mg} / \mathrm{mL}$ FITC-BSA solution $(1 \mathrm{~mL})$ were sequentially added into an $5 \mathrm{~mL}$ Eppendorf tube containing 1 $\mathrm{mL} \mathrm{WS}_{2}$ or $\mathrm{MoS}_{2}$ suspensions $(5 \mathrm{mg} / \mathrm{mL})$. The mixtures were sufficiently dispersed in a water bath sonication for $10 \mathrm{~min}$, followed by $2 \mathrm{~h}$ reaction at room temperature under magnetic stirring. The resulting FITC-BSA labeled $\mathrm{WS}_{2}$ and $\mathrm{MoS}_{2}$ pellets were collected by centrifugation at $18,000 \mathrm{rpm}$ for $5 \mathrm{~min}$. After washing by DI water for five times, all these TMD nanomaterials were collected by centrifugation, quantified by ICP-OES to form $5 \mathrm{mg} / \mathrm{mL}$ stock solutions and stored in brown glass vials at $4{ }^{\circ} \mathrm{C}$. These materials were characterized by AFM (Dimension Icon, Germany), confocal Raman microscopy (HR-800, JY, France), XPS (EXCALAB 250 XI, Thermo Fisher Scientific, USA), EPR (MS-5000, Magnettech, Germany), HR-TEM (Titan Cubed, Thermo Fisher Scientific, USA) and dynamic light scattering (Zetasizer Nano ZS90, Malvern).

Preparation of TMD suspensions. TMD stock solutions were dispersed in a sonication water bath at $32 \mathrm{~W}$ for $10 \mathrm{~min}$ before adding into RPMI 1640 medium or BEGM. Desired amounts of TMD stock solutions were diluted in culture media and fully suspended by probe sonication at $20 \mathrm{~W}$ for $20 \mathrm{~s}$.

Cell transfection. PLKO $(24 \mu \mathrm{g}, 14 \mu \mathrm{L})$, shRNA (14.5 $\mu \mathrm{g}$ Trfc1, $13.3 \mu \mathrm{g}$ Trfc2, $14 \mu \mathrm{L})$, SPA $(17.9 \mu \mathrm{g}, 14.5 \mu \mathrm{L})$, pMD $(6.0 \mu \mathrm{g}, 5.3 \mu \mathrm{L})$ and $\mathrm{CaCl}_{2}(2 \mathrm{M}, 187.5 \mu \mathrm{L})$ solutions were sequentially added into a $2 \mathrm{~mL}$ Eppendorf tube with $1.5 \mathrm{~mL} \mathrm{DI} \mathrm{H} \mathrm{H}_{2} \mathrm{O}$ as DNA components. Aliquot of $1.5 \mathrm{~mL} \mathrm{~N}, \mathrm{~N}$-bis(2-hydroxyethyl)-2-aminoethanesulfonic acid (BES) buffer was added into a $15 \mathrm{~mL}$ tube. Meanwhile, $\mathrm{CaCl}_{2}$ solution and DNA components were uniformly mixed with BES buffer and incubated for $15 \mathrm{~min}$ at room temperature. The resulting solution was added into 293 T cells cultured till 50\% confluency in Dulbecco's modified eagle medium (DMEM) medium (Gibco, USA) in a $75 \mathrm{~cm}^{2}$ flask. The post-transfection viral supernatants were collected twice at the $24 \mathrm{~h}$ and $48 \mathrm{~h}$. Then the viral solution was acquired by centrifugation of collected supernatants at $3000 \mathrm{~g}$ for $15 \mathrm{~min}$ through a filter $(0.45 \mu \mathrm{m}$ pore size $)$ and concentrated to $2 \mathrm{~mL}$. Ultimately, aliquots of $20 \mu \mathrm{L}$ viral solution were added into $10 \mathrm{~mL}$ BEGM or c-RPMI 1640 media to incubate with BEAS-2B and THP-1 cells with $50 \%$ confluency at $37^{\circ} \mathrm{C}$, respectively. After $24 \mathrm{~h}$, the supernatants were replaced with complete media. The stable clones with GFP green fluorescence were selected in puromycin $(10 \mu \mathrm{g} / \mathrm{mL})$.

MTS and ATP assays. BEAS-2B and THP-1 cells were cultured in RPMI 1640 medium supplemented with $10 \%$ fetal bovine serum (Gemini, Woodland, USA) and BEGM (Lonza, Walkersville, USA), respectively. While aliquots of $100 \mu \mathrm{L}$ of THP-1 cell suspensions containing $1 \mu \mathrm{g} / \mathrm{mL}$ PMA were added in 96-well plates at $3 \times 10^{4}$ cells/well, BEAS-2B cell suspensions were seeded in plates at $2 \times 10^{4}$ cells/ well. After overnight incubation, the cell media in 96-well plates were removed and replaced by aliquots of $100 \mu \mathrm{L}$ TMD suspensions at $0,25,50,100$, and $200 \mu \mathrm{g} / \mathrm{mL}$. After $6,12,24$, and $48 \mathrm{~h}$ culture at $37^{\circ} \mathrm{C}$, the supernatants in each well were replaced by $120 \mu \mathrm{L}$ of MTS working solution $(5 \mathrm{mg} / \mathrm{mL})$ in phenol red free media. After $2 \mathrm{~h}$ incubation, the plates were centrifuged at $3000 \mathrm{rpm}$ for $5 \mathrm{~min}(5810 \mathrm{R}$, eppendorf, Germany) to collect the supernatants, which were transferred into 96 well plates $\left(100 \mu \mathrm{L} /\right.$ well) to read $\mathrm{OD}_{490}$ values by a microplate reader (BioTek, Synergy neo, USA). Meanwhile, the residual cells were lyzed by ATP assay solutions. After $10 \mathrm{~min}$ incubation in a mini shaker (Kylin-Bell, QB-8001, China), the luminescence signals were recorded.

Confocal microscopy imaging. The fluorphore labeled cells were observed using a confocal laser scanning microscope (FV 1200, Olympus, Japan) by a $10 \times$ or $60 \times$ oil immersion objective lens. BEAS-2B cells and PMA-primed THP-1 cells were seeded in eight-well chambers (Catalog: 155411, Lab-Tek, USA) at $1.6 \times 10^{5}$ and $2 \times 10^{5}$ cells/well, respectively, and cultured at $37^{\circ} \mathrm{C}$ for $16 \mathrm{~h}$ before further treatments.

To detect lysosomal release of $\mathrm{Fe}^{2+}$ in BEAS-2B cells, the supernatants in each well of chambers were removed and replaced by $200 \mu \mathrm{L}$ of nanosheet suspensions 
$(100 \mu \mathrm{g} / \mathrm{mL})$ and $\mathrm{Fe}\left(\mathrm{NH}_{4}\right)_{2}\left(\mathrm{SO}_{4}\right)_{2}(100 \mu \mathrm{M})$ in BEGM. For alveolar macrophages, mice exposed to PBS, quartz $(5 \mathrm{mg} / \mathrm{Kg})$ and TMD $(1 \mathrm{mg} / \mathrm{Kg})$ suspensions by oropharyngeal aspiration for $40 \mathrm{~h}$ were sacrificed to collect cells from BALF by centrifugation (Allegra $64 \mathrm{R}$, Beckman-Coulter, USA) at $5000 \mathrm{rpm}$ for $10 \mathrm{~min}$. The cell suspensions in DMEM were seeded in eight-well chambers at $1 \times 10^{5}$ cells $/$ well. Followed by $12 \mathrm{~h}$ incubations, both BEAS-2B and alveolar macrophages were washed by PBS and stained by $10 \mu \mathrm{g} / \mathrm{mL}$ Hoechst 33342, $10 \mu \mathrm{g} / \mathrm{mL}$ FeRhoNox-1, and $20 \mu \mathrm{g} / \mathrm{mL}$ WGA in media for $1 \mathrm{~h}$ at $37^{\circ} \mathrm{C}$. Then, the cells were washed thrice by PBS for microscopy imaging at excitation wavelengths of 405,488 , and $543 \mathrm{~nm}$.

$\mathrm{H}_{2}$ DCF-DA staining kit was used to visualize ROS generation in cells. DFP $(2 \mathrm{mM})$ and DFX $(0.4 \mathrm{mM})$ were used as $\mathrm{Fe}^{2+}$ chelators to treat BEAS-2B cells for $2 \mathrm{~h}$. Then the chelator-treated and untreated cells were exposed to $100 \mu \mathrm{g} / \mathrm{mL} \mathrm{ZnO}$, $\mathrm{WS}_{2}$, and $\mathrm{MoS}_{2}$ for $12 \mathrm{~h}$ incubation at $37^{\circ} \mathrm{C}$. Followed by thrice PBS washing, the cells were incubated with $10 \mu \mathrm{g} / \mathrm{mL}$ Hoechst 33342 and $10 \mu \mathrm{g} / \mathrm{mL} \mathrm{H}_{2}$ DCF-DA in dark for $30 \mathrm{~min}$ at $37^{\circ} \mathrm{C}$. The fluorescence of DCF was examined at excitation wavelength of $488 \mathrm{~nm}$

To assess lipid peroxidation, BEAS-2B cells were exposed to $100 \mu \mathrm{g} / \mathrm{mL} \mathrm{WS}_{2}$ and $\mathrm{MoS}_{2}$ and incubated for $12 \mathrm{~h}$ at $37^{\circ} \mathrm{C}$. Cells treated with $10 \mu \mathrm{M} \mathrm{CH}$ for $2 \mathrm{~h}$ were also included as a positive control. The treated cells were washed twice by PBS and stained by Image-iT lipid peroxidation kit according to the manufacturer's protocol. After $1 \mathrm{~h}$ incubation at $37^{\circ} \mathrm{C}$, the stained cells were sufficiently washed by PBS for microscopy imaging at 510 and $590 \mathrm{~nm}$ emission wavelengths to visualize the oxidized and non-oxidized substrates, respectively.

To examine cell viability by LIVE/DEAD staining, BEAS-2B cells were exposed to $100 \mu \mathrm{g} / \mathrm{mL} \mathrm{WS}_{2}, \mathrm{MoS}_{2}$, WSe $2, \mathrm{MoSe}_{2}$, and BN in BEGM and incubated for $12 \mathrm{~h}$ at $37^{\circ} \mathrm{C}$. The treated cells were washed twice by PBS and incubated with $10 \mu \mathrm{g} / \mathrm{mL}$ LIVE/DEAD viability assay kit for $20 \mathrm{~min}$ at $37^{\circ} \mathrm{C}$ before confocal imaging at 517 and $617 \mathrm{~nm}$.

Hemolysis assay. Blood from C57BL/6 mouse were suspended in $20 \mathrm{~mL}$ pre-cold PBS at $4{ }^{\circ} \mathrm{C}$ and sufficiently washed and centrifuged at $3000 \mathrm{rpm}$ until the supernatant is visually clear. The cell pellets were resuspended in PBS at a density of $1 \times$ $10^{8}$ cells $/ \mathrm{mL}$. Aliquots of cell suspensions $(490 \mu \mathrm{L})$ were added into $1.5 \mathrm{~mL}$ eppendorf tubes containing $10 \mu \mathrm{L}$ nanoparticle suspensions $(5 \mathrm{mg} / \mathrm{mL})$. The red blood cells exposed to $10 \mu \mathrm{L}$ of $\mathrm{DI} \mathrm{H}_{2} \mathrm{O}$ and $0.1 \%$ Triton X-100 were included as negative and positive controls, respectively. After $2 \mathrm{~h}$ incubation at $37^{\circ} \mathrm{C}$, the supernatants were collected by centrifugation at $20,000 \mathrm{rpm}$ for $10 \mathrm{~min}$ and transferred into 96 -well plates $(100 \mu \mathrm{L} /$ well $)$ to detect the absorbance of released hemoglobin by a microplate reader (BioTek, Synergy neo, USA) at $541 \mathrm{~nm}$.

Using Nile Red labeled liposomes to simulate TMD-membrane interactions Liposomes were prepared by thin-film ultrasonication method ${ }^{52}$. In detail, $1 \mathrm{~mL}$ of $10 \mathrm{mg} / \mathrm{mL}$ DSPC was dispersed in $6 \mathrm{~mL}$ chloroform in a round bottom flask. The lipid film was prepared by rotary evaporation at $60^{\circ} \mathrm{C}$. Then the lipid film was hydrated in $10 \mathrm{~mL} \mathrm{DI} \mathrm{H}_{2} \mathrm{O}$ by water-bath sonication $(60 \mathrm{~W})$ for $30 \mathrm{~min}$. The resulted liposomes $(1 \mathrm{mg} / \mathrm{mL})$ were collected by ultrasonication at $20,000 \mathrm{rpm}$ for $5 \mathrm{~min}$, and resuspended in $1 \mathrm{~mL} 8 \mu \mathrm{g} / \mathrm{mL}$ Nile red for $2 \mathrm{~h}$ incubation at room temperature. After that, the labeled liposomes were washed thrice by centrifugation at $20,000 \mathrm{rpm}$ for $5 \mathrm{~min}$ and suspended in $1 \mathrm{~mL} \mathrm{DI} \mathrm{H}_{2} \mathrm{O}$. Nanosheets $(200 \mu \mathrm{g} / \mathrm{mL})$ were incubated with $1 \mathrm{~mL}$ labeled liposomes or $\mathrm{DI}_{2} \mathrm{O}$ (blank) at $37^{\circ} \mathrm{C}$ for $4 \mathrm{~h}$. The suspensions were centrifuged at $10,000 \mathrm{rpm}$ for $10 \mathrm{~min}$ to collect nanosheet pellets, followed by twice washing in DI $\mathrm{H}_{2} \mathrm{O}$. The TMD pellets were subsequently dispersed in $100 \mu \mathrm{L}$ DI $\mathrm{H}_{2} \mathrm{O}$ to examine the fluorescence of labeled lipids at excitation wavelength of $543 \mathrm{~nm}$.

Abiotic DCF assay. $\mathrm{H}_{2}$ DCF-DA $(50 \mu \mathrm{g})$ was hydrolyzed by incubation with $280 \mu \mathrm{L}$ of $0.01 \mathrm{M} \mathrm{NaOH}$ in dark at room temperature for $30 \mathrm{~min}$. The resulted $\mathrm{H}_{2} \mathrm{DCF}$ solution was diluted with $1720 \mu \mathrm{L}$ PSF to form working solutions $(25 \mu \mathrm{g} / \mathrm{mL})$. Aliquots of $5 \mu \mathrm{L}$ nanosheet suspensions at $5 \mathrm{mg} / \mathrm{mL}$ were added into each well in a 96-multiwell black plate (Corning, USA), and subsequently mixed with $95 \mu \mathrm{L}$ $\mathrm{H}_{2} \mathrm{DCF}$ working solution. After $2 \mathrm{~h}$ incubation at room temperature, the fluorescence of each well was recorded at $490 \mathrm{~nm}$ excitation and $520 \mathrm{~nm}$ emission wavelengths by a microplate reader.

Western blotting. BEAS-2B cells, alveolar macrophages and lung tissues treated with pharmacological agents or TMDs were lysed in a RIPA lysis buffer. The protein concentrations were determined and adjusted by Bradford assay. The cell lysates were separated on a $12 \%$ SDS-polyacrylamide gel (Beyotime, Shanghai, China) at $120 \mathrm{~V}$ and transferred to a nitrocellulose membrane at $300 \mathrm{~mA}$. The membranes were blocked with 5\% milk (Biofroxx, Einhausen, Germany) in $0.1 \%$ PBS/Tween for $2 \mathrm{~h}$ at room temperature, and then incubated with primary antibody (1/1000 in blocking buffer) for $16 \mathrm{~h}$ at $4{ }^{\circ} \mathrm{C}$. After five-time washing with PBS/ Tween and incubation with HRP-conjugated secondary antibody (1/1000 in PBS) for $1 \mathrm{~h}$ at room temperature, membranes were sufficiently washed by PBS/Tween 20 at a $5 \mathrm{~min}$ interval for five times. A freshly prepared ECL hypersensitive chemiluminescence solution was used to develop the membranes, which were imaged by multi-color fluorescence chemiluminescence imaging analysis system (FluorChem M, Alpha, USA). The unprocessed blot scans were added in Supplementary Fig. 13.
Animal experiments. Eight-week-old female C57BL/6 mice, which were obtained from Nanjing Peng Sheng Biological Technology (Nanjing, Jiangsu, China), were housed in Laboratory Animal Center of Soochow University. Our animal protocols were approved by the Committee of Animal Research and Ethics in Soochow University. Mice were exposed to $0.5,1,2,4 \mathrm{mg} / \mathrm{Kg} \mathrm{WS}_{2}$, or $1 \mathrm{mg} / \mathrm{Kg} \mathrm{MoS}_{2}$, ss$\mathrm{WS}_{2}$, me- $\mathrm{MoS}_{2}$, and $\mathrm{MoSe}_{2}$ by oropharyngeal aspiration. In detail, $2 \mathrm{D}$ nanosheets suspended in PBS were instilled at the back of the tongue with $50 \mu \mathrm{L}$ suspensions in anesthetized animals $(n=6)$. Animals instilled $50 \mu \mathrm{L}$ PBS and quartz solutions $(5 \mathrm{mg} / \mathrm{Kg})$ were used as vehicle and positive controls, respectively. After $40 \mathrm{~h}$ exposure, mice were sacrificed to acquire BALF. While the immune cells in BALF were collected by centrifugation at $8000 \mathrm{rpm}$ for cell counting, the supernatants were used for detection of LIX, IL- $1 \beta$, and TNF- $\alpha$ by ELISA. The lung tissues were fixed for H\&E staining to examine pathology changes.

Statistics. Data analysis was performed by Student $t$-test. The difference is regarded as statistical significance if $p<0.05$. Data are reported as the mean \pm standard deviation from at least three replicates.

Reporting summary. Further information on research design is available in the Nature Research Reporting Summary linked to this article.

\section{Date availability}

The datasets generated and/or analysed during the current study are available in the Harvard Dataverse repository, https://dataverse.harvard.edu/dataset.xhtml? persistentId=doi:10.7910/DVN/OZLXPB.

Received: 7 September 2019; Accepted: 23 June 2020; Published online: 13 July 2020

\section{References}

1. Lee, J.-H. et al. General and programmable synthesis of hybrid liposome/metal nanoparticles. Sci. Adv. 2, e1601838 (2016).

2. Xue, X. et al. Trojan Horse nanotheranostics with dual transformability and multifunctionality for highly effective cancer treatment. Nat. Commun. 9, 3653 (2018).

3. Nagai, H. et al. Diameter and rigidity of multiwalled carbon nanotubes are critical factors in mesothelial injury and carcinogenesis. Proc. Natl Acad. Sci. USA. 108, E1330-1338 (2011)

4. Li, R. et al. Interference in autophagosome fusion by rare earth nanoparticles disrupts autophagic flux and regulation of an interleukin- $1 \beta$ producing inflammasome. ACS Nano 8, 10280-10292 (2014).

5. Cai, X. et al. Multi-hierarchical profiling the structure-activity relationships of engineered nanomaterials at nano-bio interfaces. Nat. Commun. 9, 4416 (2018).

6. Li, R. et al. Surface oxidation of graphene oxide determines membrane damage, lipid peroxidation, and cytotoxicity in macrophages in a pulmonary toxicity model. ACS Nano 12, 1390-1402 (2018).

7. Gao, M. et al. Two-dimensional Tin Selenide (SnSe) nanosheets capable of mimicking key dehydrogenases in cellular metabolism. Angew. Chem. 9, 3647-3652 (2020).

8. Chng, E. L., Sofer, Z. \& Pumera, M. $\mathrm{MoS}_{2}$ exhibits stronger toxicity with increased exfoliation. Nanoscale 6, 14412-14418 (2014).

9. Wang, X. et al. Differences in the toxicological potential of $2 \mathrm{D}$ versus aggregated molybdenum disulfide in the lung. Small 11, 5079-5087 (2015).

10. McManus, D. et al. Water-based and biocompatible $2 \mathrm{D}$ crystal inks for allinkjet-printed heterostructures. Nat. Nanotechnol. 12, 343-350 (2017).

11. Mei, L. et al. Translocation, biotransformation-related degradation, and toxicity assessment of polyvinylpyrrolidone modified $2 \mathrm{H}$ nano- $\mathrm{MoS}_{2}$. Nanoscale 11, 4767-4780 (2019).

12. Stockwell, B. R. et al. Ferroptosis: a regulated cell death nexus linking metabolism, redox biology, and disease. Cell 171, 273-285 (2017).

13. Guiney, S. J., Adlard, P. A., Bush, A. I., Finkelstein, D. I. \& Ayton, S. Ferroptosis and cell death mechanisms in Parkinson's disease. Neurochem. Int. 104, 34-48 (2017)

14. Alim, I. et al. Selenium drives a transcriptional adaptive program to block ferroptosis and treat stroke. Cell 177, 1262-1279 (2019).

15. Voorde, J. V. et al. Improving the metabolic fidelity of cancer models with a physiological cell culture medium. Sci. Adv. 5, eaau7314 (2019).

16. Mai, T. T. et al. Salinomycin kills cancer stem cells by sequestering iron in lysosomes. Nat. Chem. 9, 1025-1033 (2017).

17. Kim, S. E. et al. Ultrasmall nanoparticles induce ferroptosis in nutrientdeprived cancer cells and suppress tumour growth. Nat. Nanotechnol. 11, 977-985 (2016) 
18. Chowdhury, R. K., Maiti, R., Ghorai, A., Midya, A. \& Ray, S. K. Novel silicon compatible $\mathrm{p}-\mathrm{WS}_{2}$ 2D/3D heterojunction devices exhibiting broadband photoresponse and superior detectivity. Nanoscale 8, 13429-13436 (2016).

19. Zhang, $\mathrm{H}$. et al. Molybdenum disulfide $\left(\mathrm{MoS}_{2}\right)$ as a broadband saturable absorber for ultra-fast photonics. Opt. Express 22, 7249-7260 (2014).

20. Chen, C.-H. et al. Hole mobility enhancement and p-doping in monolayer $\mathrm{WSe}_{2}$ by gold decoration. 2D Mater. 1, 034001 (2014).

21. Rosenberger, M. R., Chuang, H.-J., McCreary, K. M., Hanbicki, A. T., Sivaram, S. V. \& Jonker, B. T. Nano-"squeegee" for the creation of clean 2D material interfaces. ACS Appl. Mater. Interfaces 10, 10379-10387 (2018).

22. Geng, R. et al. Bio-inspired synthesis of highly crystallized hexagonal boron nitride nanosheets. Ceram. Int. 44, 14228-14235 (2018).

23. Hong, J. et al. Nitric oxide production by the vacuolar-type (H+)-ATPase inhibitors bafilomycin A and concanamycin A and its possible role in apoptosis in RAW 264.7 cells. J. Pharmacol. Exp. Ther. 319, 672-681 (2006).

24. Chung, $H$. et al. NLRP3 regulates a non-canonical platform for caspase-8 activation during epithelial cell apoptosis. Cell Death Differ. 23, 1331-1346 (2016).

25. Zhang, G., Wang, G., Liu, Y., Liu, H., Qu, J. \& Li, J. Highly active and stable catalysts of phytic acid-derivative transition metal phosphides for full water splitting. J. Am. Chem. Soc. 138, 14686-14693 (2016).

26. Hirayama, T., Okuda, K. \& Nagasawa, H. A highly selective turn-on fluorescent probe for iron (II) to visualize labile iron in living cells. Chem. Sci. 4, 1250-1256 (2013).

27. Feng, H. et al. Transferrin receptor is a specific ferroptosis marker. Cell Rep. 30, 3411-3423.e7 (2020).

28. Gao, M., Monian, P., Quadri, N., Ramasamy, R. \& Jiang, X. Glutaminolysis and transferrin regulate ferroptosis. Mol. Cell 59, 298-308 (2015).

29. Ma, S., Henson, E., Chen, Y. \& Gibson, S. Ferroptosis is induced following siramesine and lapatinib treatment of breast cancer cells. Cell Death Dis. 7 , e2307 (2016)

30. Puzyn, T., Leszczynska, D. \& Leszczynski, J. Toward the development of "nano-QSARs": advances and challenges. Small 22, 2494-5099 (2009).

31. Liu, R. et al. Classification NanoSAR development for cytotoxicity of metal oxide nanoparticles. Small 8, 1118-1126 (2011).

32. Chee, S.-S. Sulfur vacancy-induced reversible doping of transition metal disulfides via hydrazine treatment. Nanoscale 9, 9333-9339 (2017).

33. Sim, D. M. et al. Controlled doping of vacancy-containing few-layer MoS2 via highly stable thiol-based molecular chemisorption. ACS Nano 12, 12115-12123 (2015).

34. Amani, M. et al. Near-unity photoluminescence quantum yield in $\mathrm{MoS}_{2}$. Science 350, 1065-1068 (2015).

35. Velusamy, D. B. et al. Flexible transition metal dichalcogenide nanosheets for band-selective photodetection. Nat. Commun. 6, 8063 (2015).

36. Kang, K. et al. High-mobility three-atom-thick semiconducting films with wafer-scale homogeneity. Nature 520, 656-660 (2015).

37. Ciarrocchi, A., Avsar, A., Ovchinnikov, D. \& Kis, A. Thickness-modulated metal-to-semiconductor transformation in a transition metal dichalcogenide. Nat. Commun. 9, 919 (2018)

38. Berghauser, G. et al. Inverted valley polarization in optically excited transition metal dichalcogenides. Nat. Commun. 9, 971 (2018).

39. Cao, T. et al. Valley-selective circular dichroism of monolayer molybdenum disulphide. Nat. Commun. 3, 887 (2012).

40. $\mathrm{Yu}, \mathrm{W}$. J. et al. Unusually efficient photocurrent extraction in monolayer van der Waals heterostructure by tunnelling through discretized barriers. Nat. Commun. 7, 13278 (2016).

41. Agnihotri, P., Dhakras, P. \& Lee, J. U. Bipolar junction transistors in twodimensional $\mathrm{WSe}_{2}$ with large current and photocurrent gains. Nano Lett. 16, $4355-4360$ (2016).

42. Kang, T. W. et al. 2D transition metal dichalcogenides with glucan multivalency for antibody-free pathogen recognition. Nat. Commun. 9, 2549 (2018).

43. Cai, X. et al. Molecular mechanisms, characterization methods and utilities of nanoparticle biotransformation in nanosafety assessments. Small, 1907663 (2020).

44. Caracciolo, G. et al. Stealth effect of biomolecular corona on nanoparticle uptake by immune cells. Langmuir 31, 10764-10773 (2015).

45. Huang, Y. et al. Quantitative structure-activity relationship models for predicting inflammatory potential of metal oxide nanoparticles. Environ. Health Perspect, https://doi.org/10.1289/EHP6508 (2020).
46. Wang, X. et al. Quantitative techniques for assessing and controlling the dispersion and biological effects of multiwalled carbon nanotubes in mammalian tissue culture cells. ACS Nano 4, 7241-7252 (2010).

47. Vadivelmurugan, A., Anbazhagan, R., Arunagiri, V., Laiab, J.-Y. \& Tsai, H.-C. Pluronic F127 self-assembled MoS2 nanocomposites as an effective glutathione responsive anticancer drug delivery system. RSC Adv. 9, 25592 (2019).

48. Wu, S., Liu, X., Ren, J. \& Qu, X. Glutathione depletion in a Benign manner by $\mathrm{MoS}_{2}$-based nanoflowers for enhanced hypoxia-irrelevant free-radical-based cancer therapy. Small 15, e1904870 (2019).

49. Loke J. Pathophysiology and Treatment of Inhalation Injuries. (Yale University School of Medicine. Press, New Haven, 1986).

50. Cai, X. et al. Reduction of pulmonary toxicity of metal oxide nanoparticles by phosphonate-based surface passivation. Part. Fibre Toxicol. 14, 13 (2017).

51. Li, R. et al. Surface charge and cellular processing of covalently functionalized multiwall carbon nanotubes determine pulmonary toxicity. ACS Nano 7, 2352-7368 (2013)

52. Tsang, M. P., Kikuchi-Uehara, E., Sonnemann, G. W., Aymonier, C. \& Hirao, M. Evaluating nanotechnology opportunities and risks through integration of life-cycle and risk assessment. Nat. Nanotechnol. 12, 734-739 (2017).

\section{Acknowledgements}

This work was supported by the Key Projects for International Science and Technology Cooperation Program, Ministry of Science and Technology of China (2018YFE0120400) grants from the National Natural Science Foundation of China (31671032, 21976126), and Key Projects of Social Development of Jiangsu Province (BE2018653).

\section{Author contributions}

S.X., Z.C., and R.L. conceived and designed the study. S.X. performed most of the experiments. D.W. performed the confocal microscopy imaging of $\mathrm{Fe}^{2+}$ in cells. Y.P. synthesized the liposomes. W.L. and W.W. characterized the TMD materials. S.L. and C.Y. contributed in TfR-KD experiments. R.M. and M.G. contributed in data analysis. The writing of the paper was led by R.L. with participation from S.X. and H.Z.

\section{Competing interests}

The authors declare no competing interests.

\section{Additional information}

Supplementary information is available for this paper at https://doi.org/10.1038/s41467020-17300-7.

Correspondence and requests for materials should be addressed to R.L.

Peer review information Nature Communications thanks Donna Zhang and other, anonymous, reviewers for their contributions to the peer review of this work. Peer review reports are available.

Reprints and permission information is available at http://www.nature.com/reprints

Publisher's note Springer Nature remains neutral with regard to jurisdictional claims in published maps and institutional affiliations.

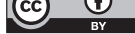

Open Access This article is licensed under a Creative Commons Attribution 4.0 International License, which permits use, sharing, adaptation, distribution and reproduction in any medium or format, as long as you give appropriate credit to the original author(s) and the source, provide a link to the Creative Commons license, and indicate if changes were made. The images or other third party material in this article are included in the article's Creative Commons license, unless indicated otherwise in a credit line to the material. If material is not included in the article's Creative Commons license and your intended use is not permitted by statutory regulation or exceeds the permitted use, you will need to obtain permission directly from the copyright holder. To view a copy of this license, visit http://creativecommons.org/ licenses/by/4.0/.

(C) The Author(s) 2020 